\title{
CALCÁRIOS OOLITICOS DE TAGUAÍ (SP) E SEU POSSÍVEL SIGNIFICADO PALEOAMBIENTAL NA DEPOSIÇÃO DA FORMAÇÃO ESTRADA NOVA
}

\author{
KENITIRO SUGUIO*, ENEAS SALATI** e JOSE H. BARCELOS***
}

\begin{abstract}
The paleoenvironmental significance of a typical oolitic limestone from the Permian Estrada Nova Formation of the Paraná Basin, Brazil, was studied.

The sedimentary structures; the mineralogy and petrography and the chemical composition (major, minor and trace elements and stable isotopes) were described. The informations suggest that a shallow salt water (marine or lacustrine), relatively agitated and submitted to intensive evaporation characterized the deposition of these limestones.
\end{abstract}

INTRODUÇÃ A Formação Estrada Nova, nome proposto por White (1908), corresponde no Estado de São Paulo à Formação Corumbatai dos geblogos da antiga Comissão Geográfica e Geológica. É constituída por sedimentos com espessuras que variam de $130 \mathrm{~m}$ a $200 \mathrm{~m}$, aumentando para NW e diminuindo para NE.

Esta unidade geológica, de idade permiana, é mais bem conhecida no Estado de São Paulo, ao longo do vale do Rio Corumbataí, nos arredores de Rio Claro. Para o sul do Estado pouco se conhece e, especificamente da área de calcários aqui tratados, têm-se apenas observações esparsas e algumas indicaçżes de coletas de fósseis.

A Formaçăo Estrada Nova é constituída principalmente por siltitos e folhelhos, associados a arenitos muito finos e camadas decimétricas de calcário. Os bancos de calcários, aqui estudados, constituem a única ocorrência de algum interesse econômico.

Entre os fósseis mais comuns dessa formação têm-se os lamelibrânquios, conchostráceos, peixes e plantas (madeiras silicificadas). Os lamelibrânquios ocorrem em calcários oolíticos ou em coquinas, ricos em indivíduos e geralmente ricos também em número de espécies, que chegam a quase trinta. As estruturas sedimentares singenéticas mais características da Formação Estrada Nova são as marcas onduladas com laminaçðes cruzadas e gretas de contração.

Embora Beurlen (1953) tenha feito consideraçz̃es sobre a possibilidade de terem sido esses sedimentos depositados em "mar interior", com base em evidencias paleontológicas, autores como Mezzalira (1964), Mendes e Petri (1971) e vários outros estudiosos desta unidade estratigráfica, baseados também nas características e tipos de associaçzes fossilfferas e nas estruturas sedimentares, estão mais ou menos de acordo em admitir um ambiente continental para a Formação Estrada Nova. Adianta, ainda, Mezzalira (1964:78) que a ausência de clásticos grosseiros permitiria supor que se tratasse de deposição em região aplainada e a ocorrência de marcas onduladas de pequena amplitude indicaria águas rasas.

O objetivo principal deste trabalho consistiu atacar este problema tão controvertido de um ângulo bastante diferente dos considerados até hoje. Foram estudadas as estruturas sedimentares profusamente encontradas nos calcários ooliticos, os quais foram também

*Instituto de Geociências da Universidade de São Paulo: Caixa Postal 20899, Butantã, São Paulo

**Centro de Energia Nuclear na Agricultura, Piracicaba (SP)

****Bolsista da CAPES. Pós-graduando do Instituto de Geociências da Universidade de São Paulo 
amostrados para análises químicas, petrográficas, tendo-se recorrido também à análise isotópica de $\mathrm{C}^{13} / \mathrm{C}^{12}$ e $\mathrm{O}^{18} / \mathrm{O}^{16}$, na tentativa de colaborar na elucidação deste problema.

CALCÁRIOS DA ÁREA DE TAGUAI Na porção superior da Formação Estrada Nova, constituída de siltitos, arenitos e folhelhos, estão freqüentemente encerradas massas individualizadas de calcários, em corpos de forma lenticular. Na região de Fartura (SP), incluindo a área de Taguaí, são freqüentes siltitos mais ou menos maciços de cor cinza-esverdeado-clara, em franco contraste com o ritmismo acentuado dos sedimentos síltico-argilosos da regiaxo mais ao norte do Estado de São Paulo.

Os afloramentos mais conspícuos de calcários na Formaçăo Estrada Nova deste Estado são justamente os intercalados nos siltitos, encontrados no município de Fartura. Este calcário forma uma faixa de afloramentos descontínuos na encosta da Serra de Fartura e pequenas caieiras já estiveram em funcionamento. No distrito de Taguaí afloram camadas de calcário oolítico, cuja espessura varia de $2 \mathrm{~m}$ a $6 \mathrm{~m}$. Atualmente, o material é explorado para fabricação de pó calcário, corretivo de solo, na Fazenda São Vicente. As observações contidas neste trabalho restringem-se a duas pedreiras (Pedreira Velha e Pedreira do Pau Preto) e a dados obtidos em laboratório, de amostras colhidas nessas localidades (Fig. 1).

AMOSTRAGEM DE SEDIMENTOS Foram coletadas no total 26 amostras de sedimentos, para vários tipos de estudos de laboratório, provenientes da Pedreira de Pau Preto e Pedreira Velha.

As primeiras 12 amostras da série TG foram coletadas em um caminhamento, seguindo a frente de exploração da Pedreira Velha, a partir do extremo NW para SE (Fig. 2A). A amostra TG-13 corresponde a material de preenchimento das gretas e a amostra TG-14 do sedimento gretado.

As amostras PV-1A, PV-1B até PV-4 provêm de uma seção colunar levantada a meio caminho dos extremos da Pedreira Velha (Fig. 2B).

De PP-1 a PP-5 foram obtidas em uma seção colunar medida na Pedreira de Pau Preto. As amostras PP-6 e PP.7 representam nódulo de sílex e contato camada de sílex-calcário, respectivamente, coletadas nesta pedreira (Fig. 2C).

ESTRUTURAS SEDIMENTARES Os calcários são extremamente ricos em estruturas sedimentares, principalmente de origem singenética, muitas delas de caráter vetorial,
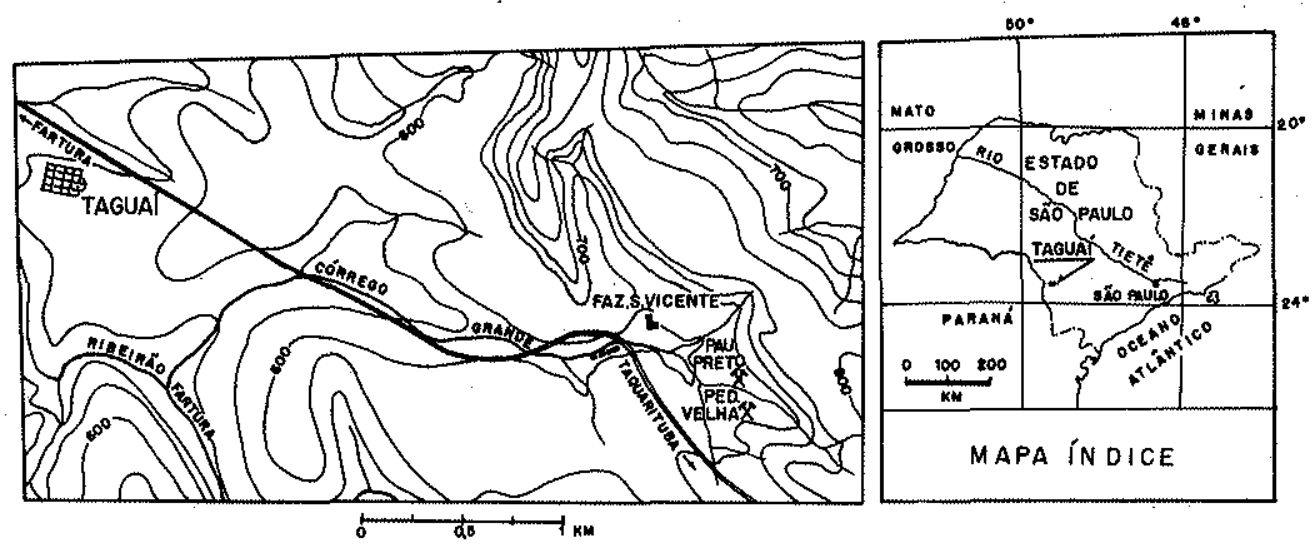

Figura 1 - Localização das pedreiras estudadas 


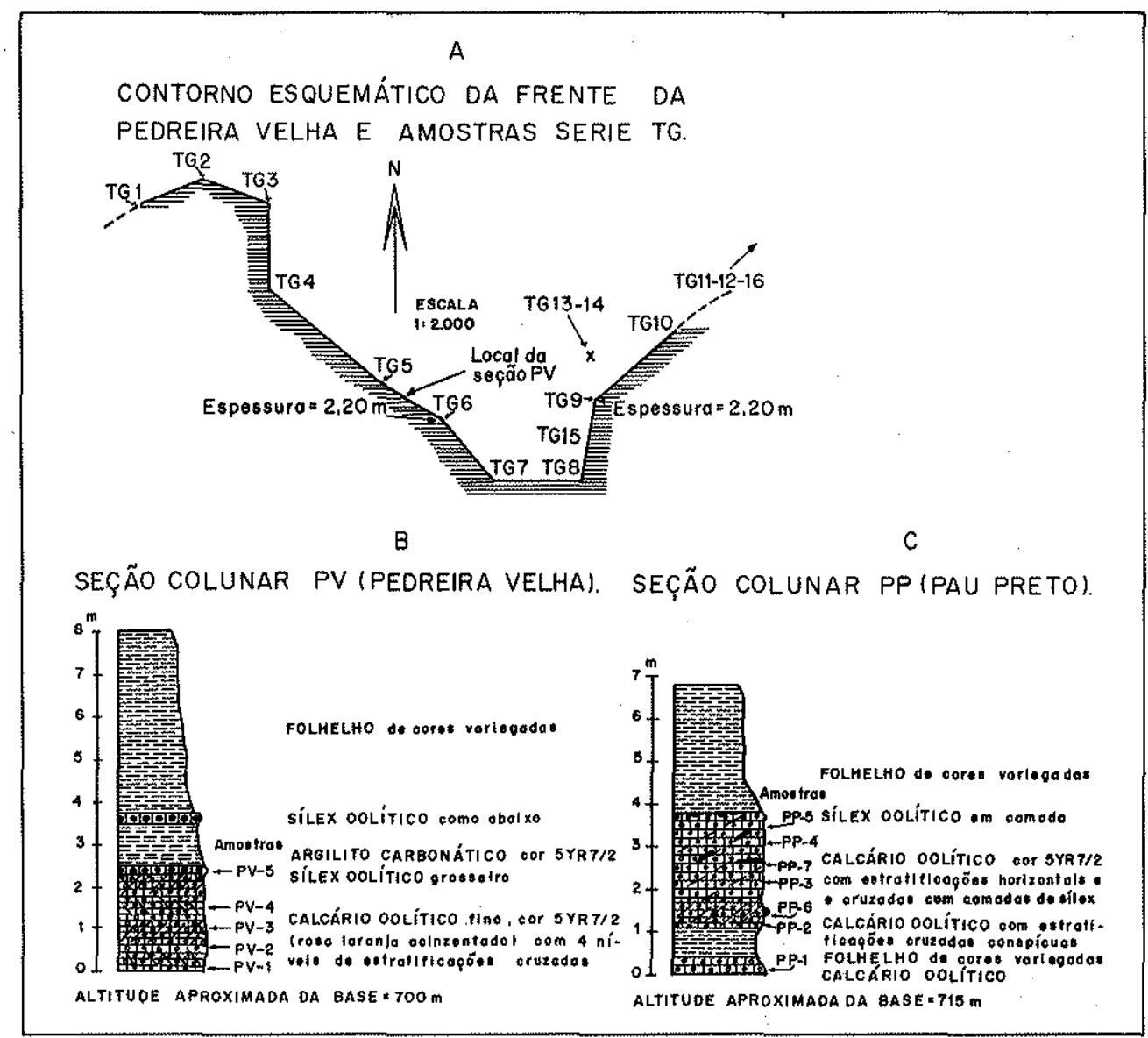

Figura 2 - Indicação de amostras de sedimentos coletadas nas pedreiras

que dão informações sobre as condições de gênese desses sedimentos. As estruturas sedimentares aqui constatadas foram as seguintes:

Estrutura oolitica Os calcários aqui tratados são oolíticos, mas este fato só é notado em exame de campo, através de observação detida com uma lupa de bolso. A grande maioria dos detalhes aqui relatados pôde ser observada em seção delgada estudada sob microscópio petrográfico.

Os contornos dos oólitos são nítidos, como nas lâminas das amostras TG-1 a TG-4, ou mais obliterados, como na seção delgada da amostra TG.5. A obliteração dos contornos ocorre por intemperismo, por silicificação ou por recristalização. Além disso, a observação sob luz paralela ressalta melhor os contornos das partículas que sob nicóis cruzados.

Quando não ocorre o obscurecimento dos contornos, as estruturas internas fibro-radiada e concêntrica são também muito bem definidas. Verifica-se, além disso, a extrema raridade de fragmentos detríticos insolúveis, presentes sob a forma de núcleos de oblitos, que teriam assim funcionado como germe de cristalização durante a gênese desses sedimentos.

Quanto às formas dos oólitos, predominam os de forma esférica, embora tenham sido constatadas partículas com estrutura laminar concêntrica mas muito alongadas e, freqüentemente, encurvadas (Foto 1A). 


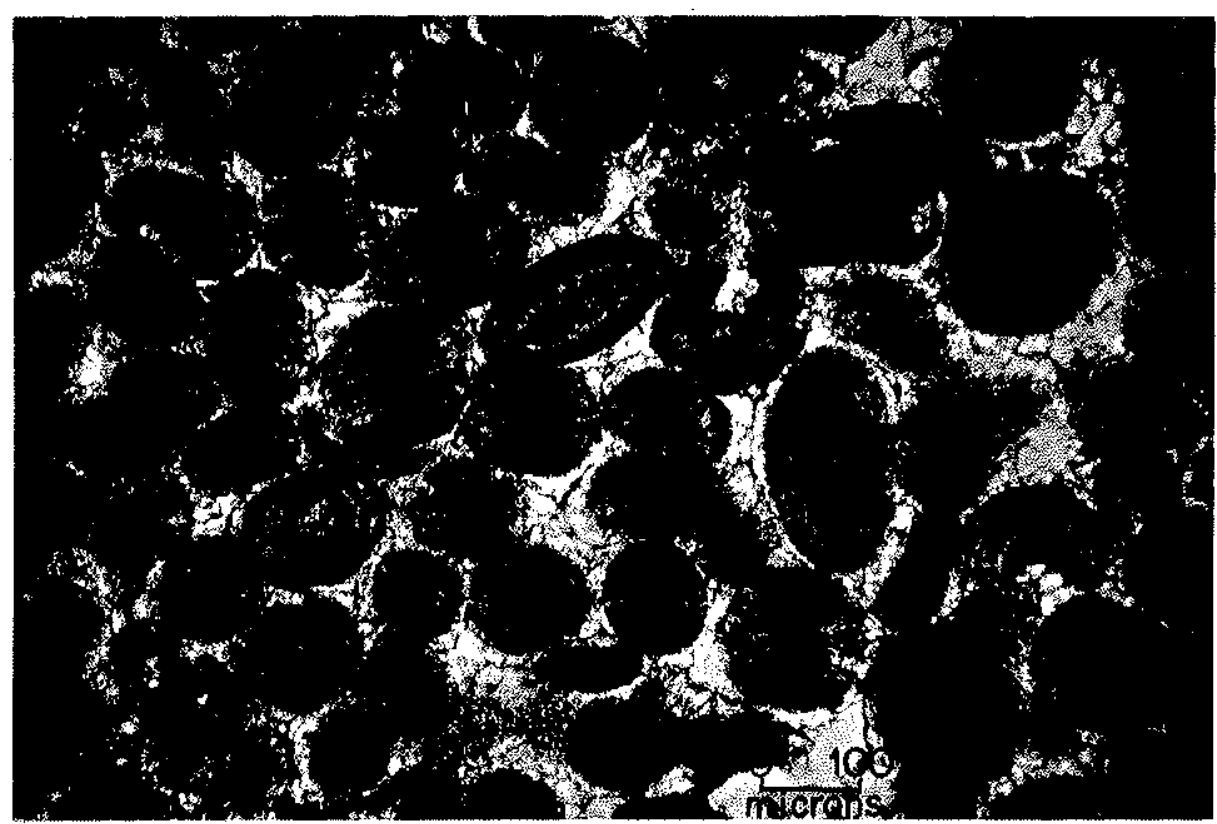

Foto $1 \mathrm{~A}$ - Oólitos de calcário apresentando estruturas concêntrica e radial. Predominam formas esferoidais mas aparecem também formas bastante achatadas

Os espaços entre os oólitos são em geral cimentados por calcita cristalina. No entanto, às vezes são deixados vazios que determinam a porosidade desses calcários; fato que acontece na lâmina da amostra TG-1, onde aparecem poros que atravessam tanto os oólitos como a zona cimentada entre os oólitos. Deve ser resultado de dissolução epigenética por soluçбes percolantes. Em geral, o cimento calcítico, que preenche os interstícios entre os oólitos, é de melhor cristalinidade que os oblitos, fato que, aliás, permitiu a preservação de contornos bastante nítidos para a maior parte dos oblitos.

Entre os oólitos aparecem freqüentemente manchas pigmentares opacas, talvez de óxido de ferro. Estas manchas parecem dispor-se também, de preferência, ao longo de camadas (lâminas das amostras TG-2 e TG-6). Nas lâminas das amostras TG-7 e TG-8 parece que a existência desses pigmentos torna os oólitos de tonalidade mais escura (acastanhadanclara), de modo que os contornos dos oblitos são muito nítidos, tanto sob nicóis descruzados como sob nicóis cruzados, realçados ainda mais pela calcita cristalina branca do cimento intersticial dos grãos.

Como será visto em outra parte deste trabalho, a granulação dos ob́litos é muito uniforme, mas aparece um nível situado no limite superior dos bancos de calcário, onde os oólitos são de dimensões maiores. Neste nível, os oólitos fogem algo da esfericidade perfeita, e fato interessante é a verificação de freqüentes fragmentos englobando 2,3 ou mais oólitos de dimensð̃es menores (Foto 1B).

A existência de estruturas sedimentares singenéticas ligadas às paleocorrentes, tais como, estratificações cruzadas e marcas onduladas assimetricas, dissipam quaisquer dúvidas sobre a origem clástica desses calcários oolíticos. No entanto, a não observância de qualquer sinal de erosão dos oólitos é também indicativa de transporte relativamente curto. Seriam enquadrados, muito corretamente, entre os sedimentos denominados por Folk (1968:1) de aloquímicos, pois foram precipitados de soluções químicas dentro da bacia de deposição e depois mobilizados a curta distância como partículas sólidas. 


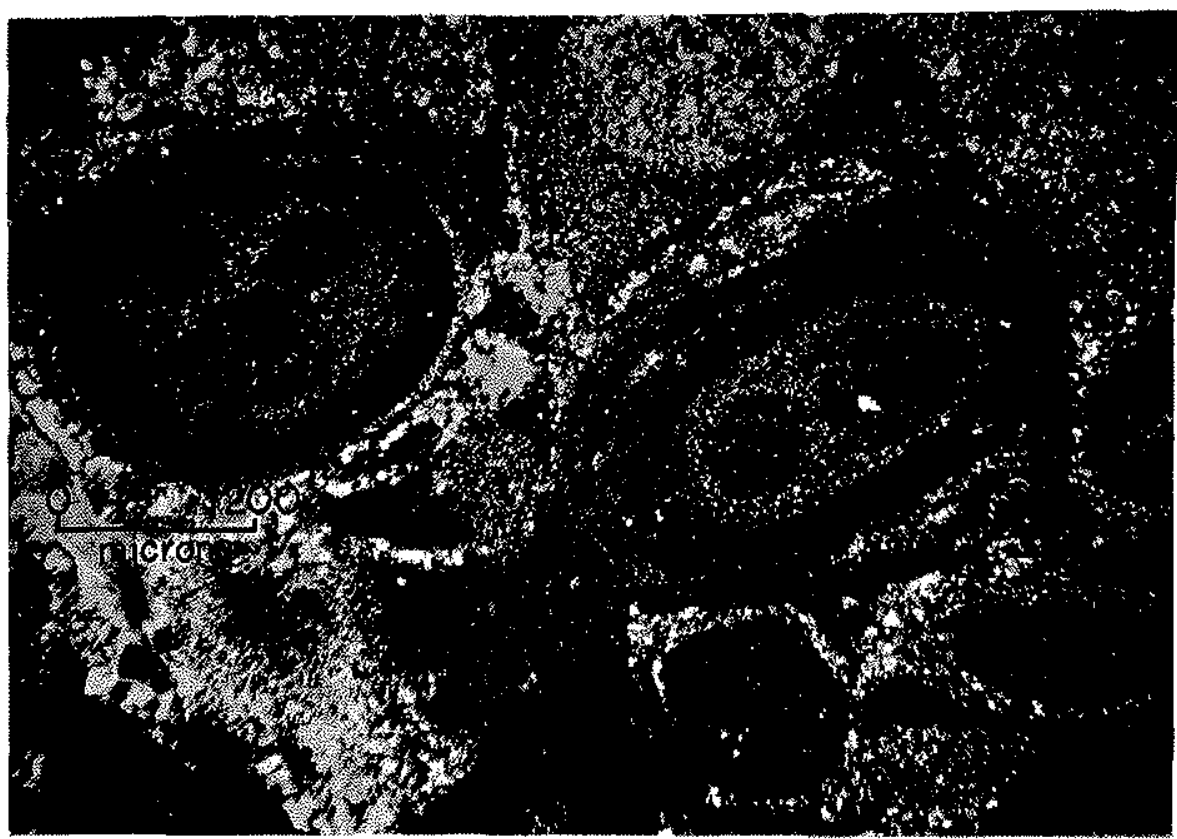

Foto 1B - Ob́litos silicificados grosseiros, podendo-se notar a presença de oólitos menores como núcleos. $\mathrm{O}$ cimento também é silicificado (calcedônia)

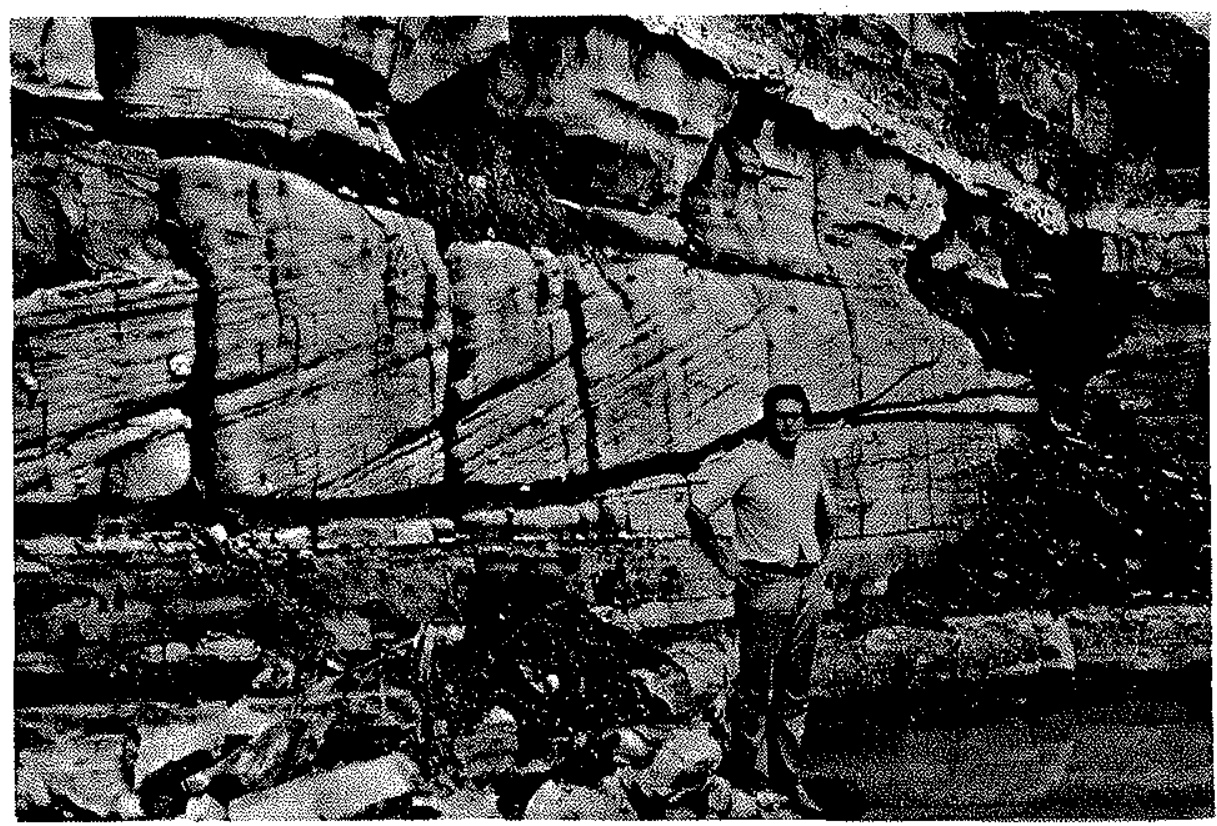

Foto 2 - Vista geral das estratificações cruzadas presentes nos calcários. Notar a presença de nódulos esféricos e de camadas de calcedônia mais salientes no afloramento (Pedreira do Pau Preto, Taguaí, SP) 
Estratificacões cruzadas As estruturas singenéticas mais freqüentes e mais desenvolvidas desses calcários são as estratificações cruzadas (Foto 2).

Adotando-se a classificação de McKee e Weir (1953), as estratificações cruzadas presentes nos calcários da Formação Estrada Nova em Taguaí podem ser enquadradas entre as estratificações cruzadas planares, que consistem de conjuntos cujas superficies de contatos inferiores são planos de erosão. Deste modo esses contatos são tabulares não tangenciais.

Quanto à magnitude, elas são de escala média, pois os comprimentos das camadas frontais estão compreendidos entre $30 \mathrm{~cm}$ e $6 \mathrm{~m}$. Além disso, quanto aos ângulos de mergulho, podem ser classificadas como sendo de baixo ângulo, pois predominam valores inferiores a $20^{\circ}$, ainda segundo os critérios estabelecidos pelos autores supramencionados.

Em uma sequiência vertical podem suceder-se de 3 a 4 níveis de estratos cruzados com $0,50 \mathrm{~m}$ a $1,00 \mathrm{~m}$ de espessura individual. Às vezes acham-se intercalados por camadas menos espessas apresentando estratificação plano paralela horizontal a sub-horizontal. Estes níveis são também aparentemente mais argilosos e impuros. Alguns conjuntos de estratificaçōes cruzadas parecem mostrar contato erosivo em forma de escavação e preenchimento, fato sugerido na Pedreira do Pau Preto.

Laminą̧ôes cruzadas de marcas onduladas As laminações cruzadas são relativamente pouco freqüentes nesses calcários. Embora maiores detalhes não pudessem ser vistos em afloramentos, possivelmente seriam enquadradas no tipo 1 da classificação de Walker (1963), que é caracterizado por forte erosão de lâminas a montante da corrente que as originou e ausência de estrutura gradativa. A litologia dessas marcas, sendo de calcário oolítico muito bem selecionado granulometricamente, condicionou a ausência completa de qualquer gradação visível (Foto 3).

Estas estruturas são mais bem desenvolvidas no folhelho carbonático da capa do calcário, onde formam freqüentemente estruturas lenticulares do tipo flaser, quando obser-

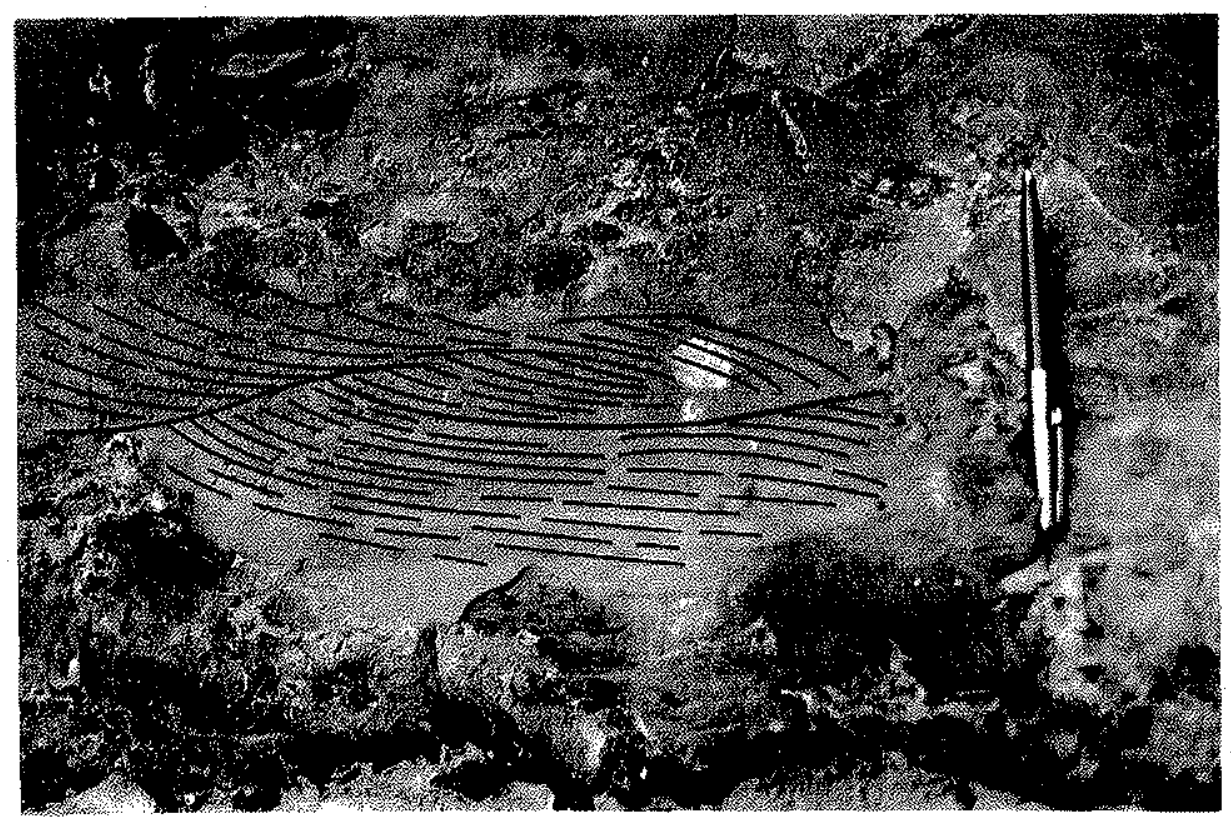

Foto 3 - Laminaç̃̃es cruzadas de migração de marcas onduladas (Pedreira Velha, Taguaí, SP) 
vadas em corte transversal ao acamamento. Neste caso são mais características do tipo 2 de Walker, compostas de co-seqüências de lâminas cruzadas formadas por migração de marcas onduladas, constituídas de areia fina e silte, alternando-se com faixas de argilitos maciços ou fracamente laminados.

Marcas onduladas As estruturas sedimentares singenéticas de marcas onduladas são, em geral, assimétricas, mas aparecem também casos de marcas simétricas.

Quanto ao tamanho, caracterizado pela amplitude e comprimento de onda das marcas, são também extremamente variáveis. Existem de corrugações assimétricas de amplitude mínima de $2 \mathrm{~mm}$ a $3 \mathrm{~mm}$ e comprimento de onda de $3 \mathrm{~cm}$ a $4 \mathrm{~cm}$ a marcas muito bem formadas com $1 \mathrm{~cm}$ de amplitude e $5 \mathrm{~cm}$ ou mais de comprimento de onda. Estes valores indicam índices das marcas (comprimento de onda/amplitude, segundo Tanner, 1967) variáveis entre 5 a 15 (Foto 4).

Outro detalhe que caracteriza essas marcas onduladas é a relativa continuidade e retilinidade das cristas e calhas que formam as marcas, sendo inclusive raras as bifurcações de cristas. Os valores medidos para o indice de retilinidade (distância paralela à crista, ao longo da qual a curvatura pode ser vista, dividida pelo afastamento da crista $\mathrm{em}$ relação à linha reta; segundo Tanner, op. cit.) forneceram valores acima de 9 , que caracterizariam marcas onduladas resultantes do vento, onda ou de quebra de onda (swash), de acordo com aquele autor, enquanto que valores menores indicariam marcas onduladas de correntes.

Medida efetuada em marca ondulada assimétrica, mais bem desenvolvida, indicou direção de crista $\mathrm{N} 70^{\circ} \mathrm{W}$ e possível rumo de corrente para NE. Neste local aparecem, logo abaixo, estratificações cruzadas que mostram direção $\mathrm{N} 60^{\circ} \mathrm{W}$ e provável rumo de corrente para $\mathrm{NE}$, com camadas frontais mergulhando $23^{\circ}$, exibindo boa concordância dos resultados. No entanto, em outro local da Pedreira Velha, na porção basal do calcário,

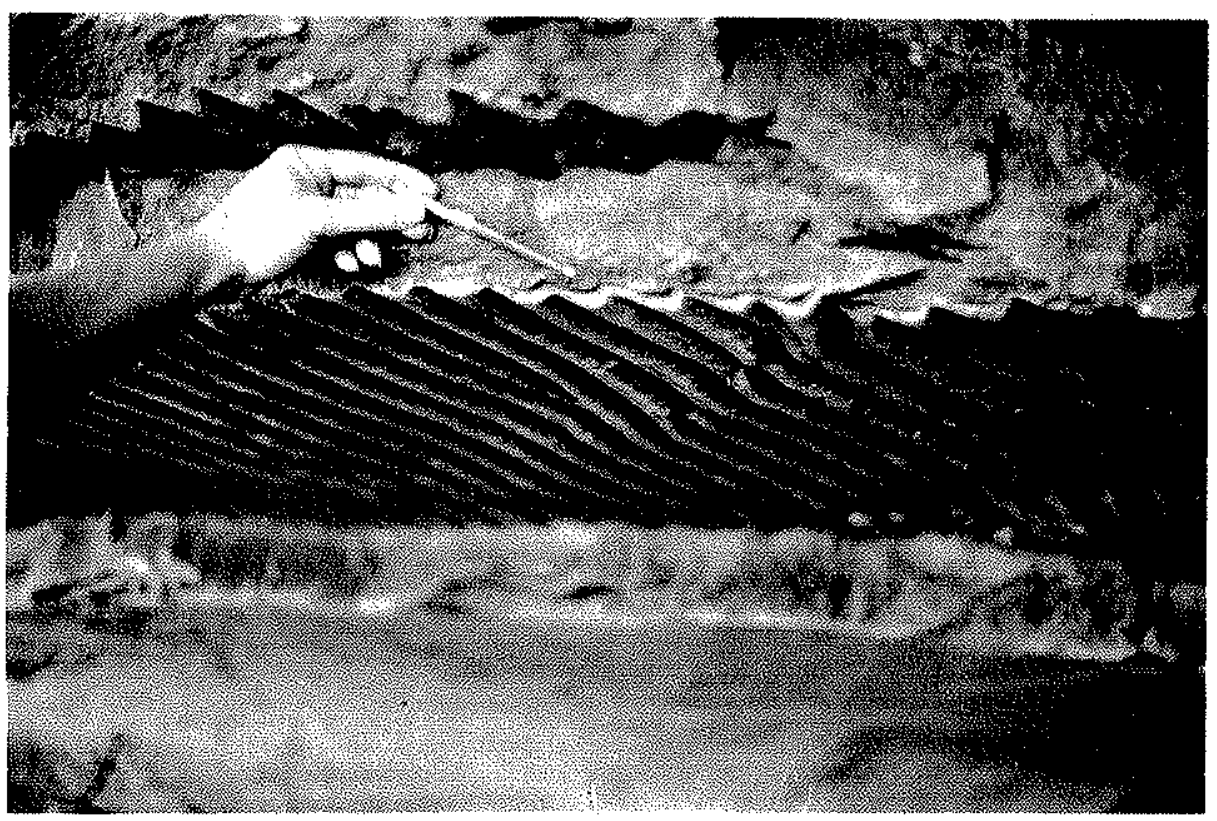

Foto 4 - Molde de marca ondulada assimétrica de calcário, encontrada no "teto" de uma pequena gruta (Pedreira Velha, Taguaí, SP) 
aparecem marcas onduladas assimétricas (de assimetria muito baixa) que sugerem direção de crista $\mathrm{N} 35^{\circ} \mathrm{E}$ e possível rumo das paleocorrentes para NW.

As marcas onduladas se repetem em vários níveis com $30 \mathrm{~cm}$ ou $40 \mathrm{~cm}$ de separação, intercaladas por estratificações cruzadas, embora as primeiras sejam bem mais raras que as últimas.

Gretas de contrafão As gretas de contração constituem as estruturas sedimentares singenéticas mais proeminentes dos sedimentos da Formação Estrada Nova. A sondagem de Araquá (município de Rio Claro, SP), efetuada pela Petrobrás S.A., atravessou sucessivos leitos com gretas de contração em sedimentos argilosos, conservadas por camadas arenosas posteriormente formadas. No entanto, essas gretas são de dimensões relativamente pequenas. Embora sejam reconhecíveis diversas gerações de gretas, correspondentes a diferentes estágios de ressecação do material, constituídas de polígonos de várias formas, sendo as primeiras gerações de dimensões maiores. Mas mesmo estas não atingem tamanhos muito maiores que $10 \mathrm{~cm}$ de diâmetro.

As gretas de contração encontradas nos sedimentos argilosos carbonáticos, da base das camadas de calcário, são impressionantes pelo tamanho avantajado das mesmas. Os polígonos de materiais gretados atingem $30 \mathrm{~cm}$ a $40 \mathrm{~cm}$ até cerca de $100 \mathrm{~cm}$ de diâmetro (Foto 5).

As formas assumidas pelos polígonos gretados são triangulares, quadrangulares, pentagonais e hexagonais, com predominância da forma quadrangular.

O material gretado é um argilito carbonático, tipo de marga, muito quebradiço. Observado em seção delgada verificou-se que praticamente $50 \%$, em área, são constituídos por calcita romboédrica muito fina, com $0,008 \mathrm{~mm}$ até $0,060 \mathrm{~mm}$ de diâmetro, disseminada entre material detrítico quartzoso (cerca de $20 \%$ ) de $0,008 \mathrm{~mm}$ a $0,020 \mathrm{~mm}$. $\mathrm{O}$ restante, cerca de $30 \%$, é constituído de matriz argilosa, muito fina, em cristais indis-

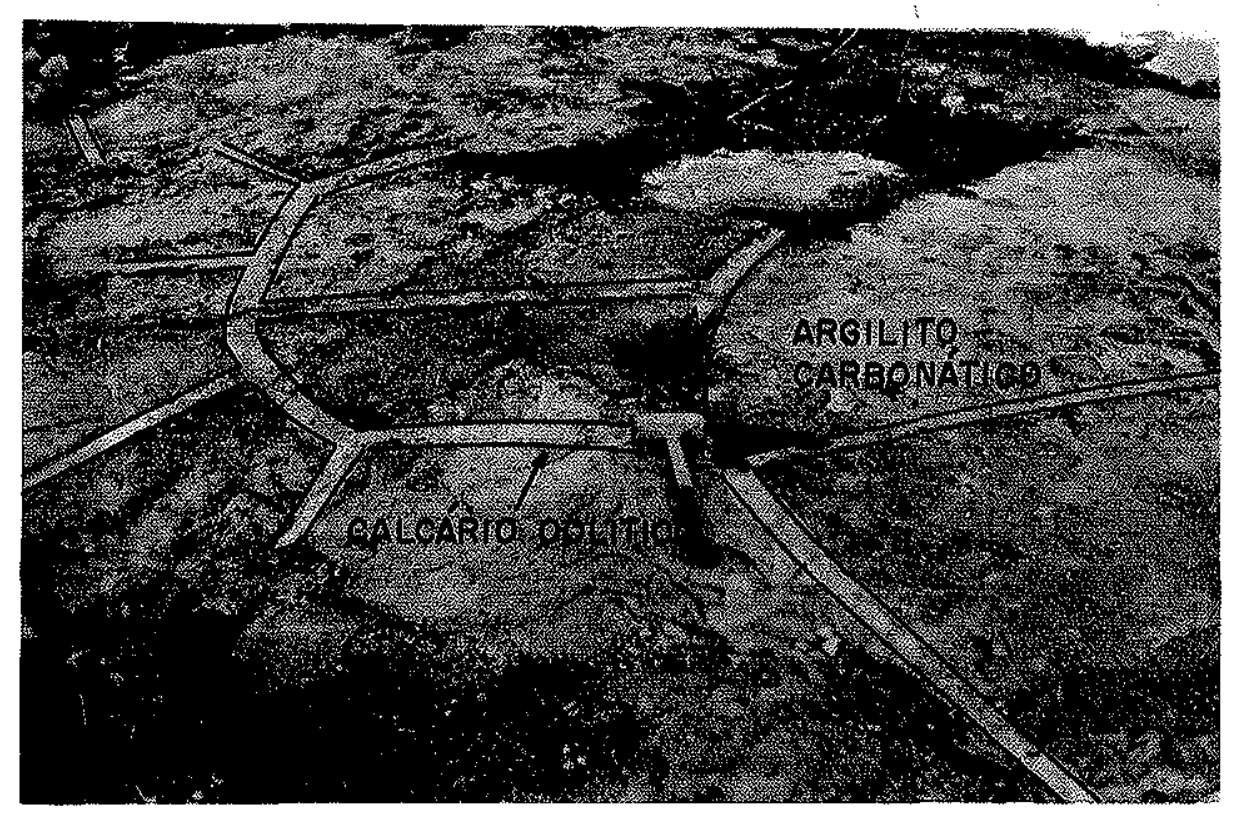

Foto 5-Gretas gigantescas em argilito carbonático preenchidas por calcário oolítico. Ocorrem na parte basal do banco de calcário (Pedreira Velha, Taguaí, SP) 
tintos mesmo com aumento de 320 vezes e cimento carbonático preenchendo os últimos espaços vazios.

O preenchimento das gretas é feito por calcário oolítico. As espessuras dos materiais de preenchimento variam de alguns centímetros a $8 \mathrm{~cm}$, com os lados paralelos e retos em plano transversal às gretas, mas diminuindo em profundidade até o desaparecimento total das gretas. Examinando-se em seção delgada constatou-se tratar de oólitos do mesmo tipo da camada calcária sobrejacente. Os clásticos insolúveis (tipo quartzo), neste calcário de preenchimento das gretas, são também raros, com certo número de oóides menores sem estruturas internas fibro-radiada e concêntrica visiveis, embora a forma perfeita esférica seja a mais comum. Como no calcário da camada sobrejacente, os oólitos não possuem núcleos detríticos e às vezes encontram-se achatados, e os espaços entre os oólitos são preenchidos por calcita cristalina. Os fragmentos clásticos insolúveis variam de $0,020 \mathrm{~mm}$ a $0,040 \mathrm{~mm}$ de diâmetro.

Microestilólitos Os estilólitos, em geral de pequenas dimensões, são relativamente raros, aparecendo mais freqüentemente na parte SE da Pedreira Velha. Nesta parte é que aparecem também mais profusamente as estruturas de marcas onduladas e de laminaçסes cruzadas de marcas onduladas.

As profundidades das partes interpenetradas dos estilólitos raramente chegam a $1 \mathrm{~cm}$ e apresentam um traçado geral ondulado estendendo-se por $1 \mathrm{~m}$ ou mais, lateralmente, e freqüentemente acabam desaparecendo.

As "cintas estilolíticas" acompanham as camadas. Nenhum caso de cintas que se cruzam, ou que cortam acamamentos, foi observado.

Parece existirem dois tipos: um tipo muito recortado, bastante parecido com o descrito por Petri e Suguio (1970) para os calcários da Formação Irati, e outro tipo menos recortado, mais regular e de dimensões maiores, com interpenetrações que chegam até

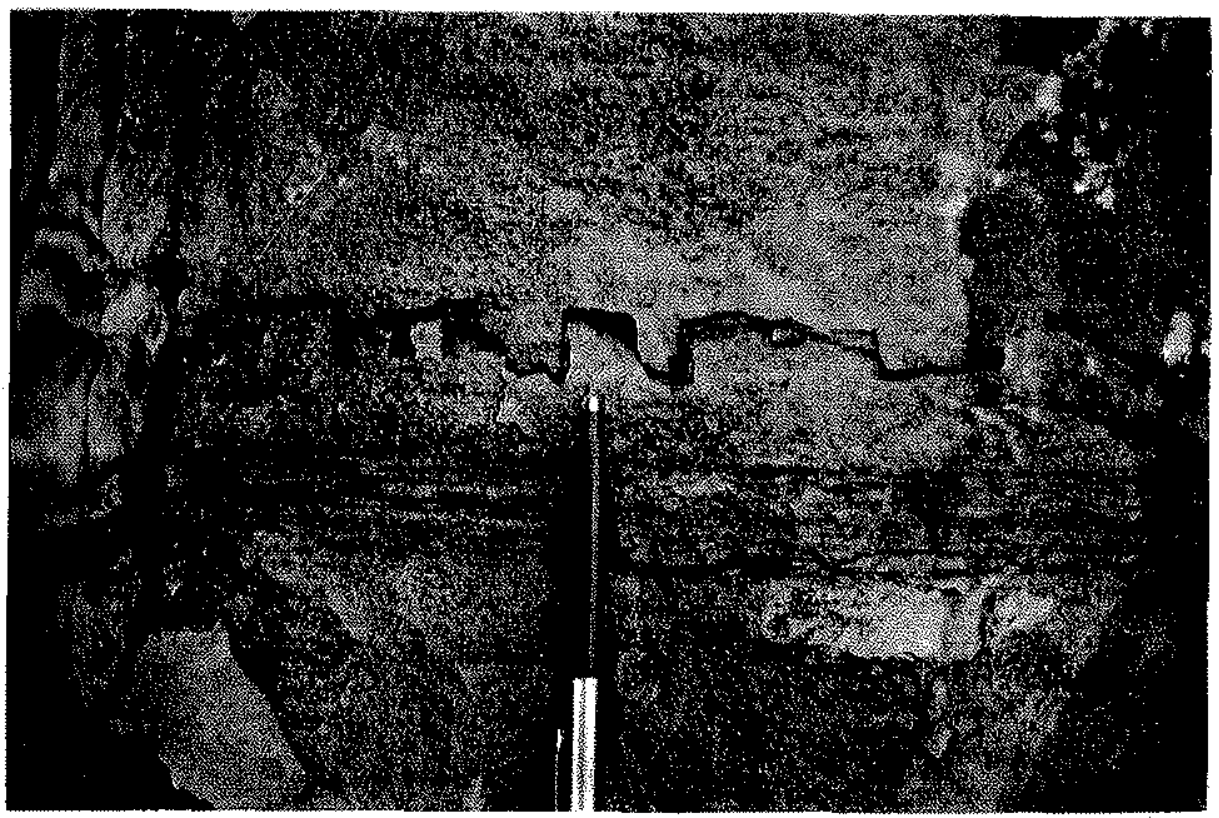

Foto 6A - Microestilólitos de dimensões centimétricas e de formas regulares em calcário (Pedreira Velha, Taguai, SP) 


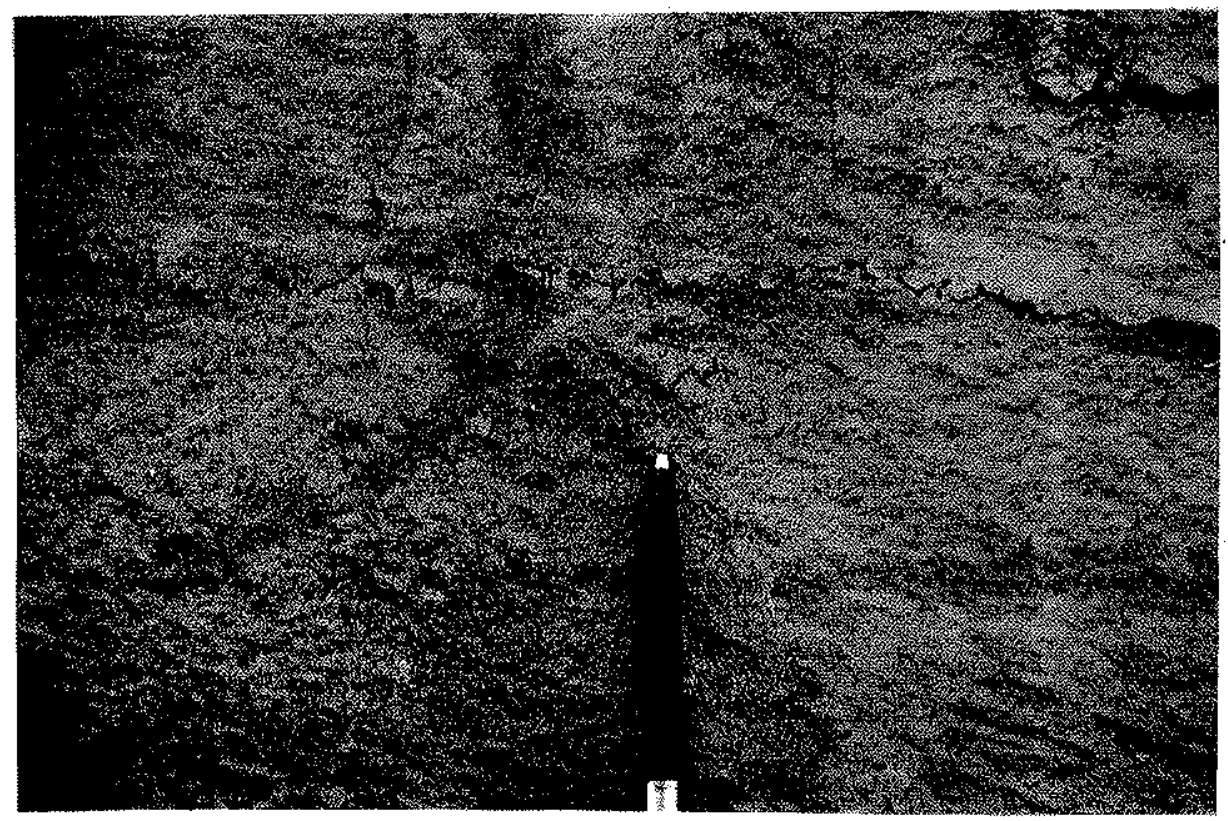

Foto $6 \mathrm{~B}$ - Microestilólitos de dimensões milimétricas e de formas irregulares em calcário (Pedreira Velha, Taguaí, SP)

$2 \mathrm{~cm}$ a $3 \mathrm{~cm}$ e acompanhando também, grosso modo, as estratificações. Aparentemente o primeiro tipo é mais comum (Fotos 6A e 6B).

Ao longo dos estilólitos desenvolvem-se materiais escuros amarelados, que devem ser óxidos de ferro percolados secundariamente.

Relações dos estilólitos com nódulos e camadas silicosas, também freqüentes nestes calcários, para se ter uma idéia da idade relativa desses eventos, não puderam ser verificadas.

Marcas de sola $\mathrm{Na}$ base das camadas de calcário, na Pedreira Velha, puderam ser vistas marcas de sola do tipo de estrutura de sobrecarga (load cast), constituídas de intumescências de $5 \mathrm{~cm}$ a $10 \mathrm{~cm}$ de altura, bastante irregulares no formato e sem orientação.

Nódulos e camadas de silex Estes calcários da Formação Estrada Nova são muito.silicificados, principalmente sob a forma de nódulos e camadas.

Os nódulos são, na maior parte das vezes, bastante esféricos e atingem dimensões desde $2 \mathrm{~cm}$ a $3 \mathrm{~cm}$ até mais de $15 \mathrm{~cm}$ de diâmetro. Parecem dispor-se ao longo de camadas. A estratificação é contínua através dos mesmos, denotando perfeitamente sua origem epigenética (Foto 7). Além disso, o exame microscópico em seção delgada desses nódulos mostrou que sua constituição é inteiramente oolítica, levemente obliterada pela silicificação, mas ainda estão presentes as estruturas internas características dos oólitos carbonáticos, quais sejam a fibro-radiada e a concêntrica. Em alguns oólitos, em vez de obliteração pela silicificação, ocorre realce das estruturas internas dos oólitos pela ferruginização. Também estão presentes formas achatadas e alongadas e ólitos imperfeitos. O cimento é constituído de calcedônia fibrosa, muitas vezes fibro-radiada. Dentro dos oólitos silicificados que constituem os nódulos são também raros os fragmentos de quartzo detrítico. 


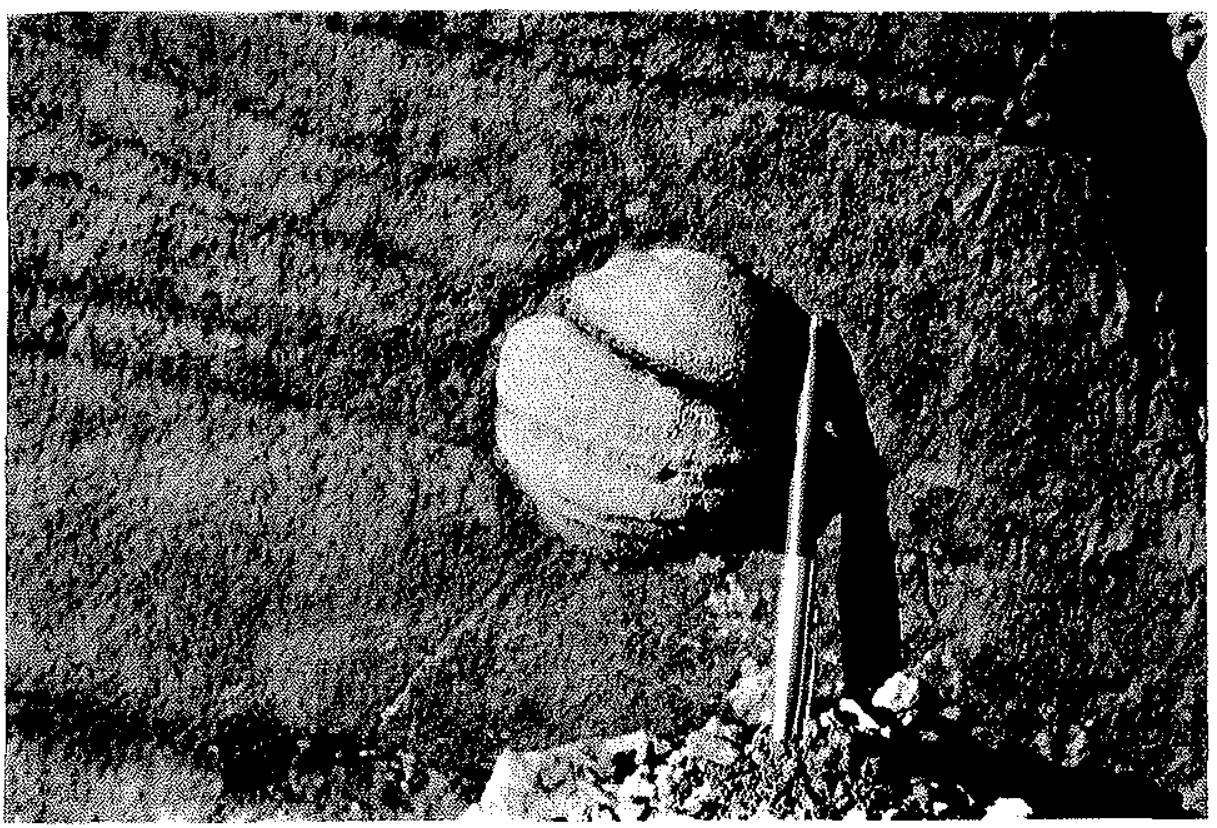

Foto 7 - Nódulo esférico de sílex mostrando a continuidade da estratificação do calcário por dentro do nódulo (Pedreira do Pau Preto, Taguaí, SP)

Os nódulos irregulares e as camadas formam outro tipo de silicificação dos calcários. Os nódulos irregulares possuem dimensões de alguns centímetros até $30 \mathrm{~cm}$ a $40 \mathrm{~cm}$, em parte rombudos, ou acompanhando o acamamento do calcário, quando são mais ou menos tabulares. As camadas de sílex são bastante tabuliformes, dispõem-se sempre acompanhando as estratificações plano-paralelas horizontais e sub-horizontais, e, mais comumente, as camadas frontais das estratificações cruzadas. Suas espessuras variam de alguns centímetros a cerca de $10 \mathrm{~cm} \mathrm{e}$, em geral, são lenticulares, desaparecendo em extensão no máximo pouco superior a $2 \mathrm{~m}$ ou $3 \mathrm{~m}$

A silicificação em camada é particuıarmente intensa no nível de oólitos mais grosseiros, de cerca de $15 \mathrm{~cm}$ de espessura, que ocorre no topo do banco de calcário. Esta camada é contínua por centenas de metros de extensão na Pedreira Velha. Foi nestes óblitos, inteiramente silicificados, que foram comumente observadas, por microscopia, estruturas de oólitos maiores englobando 3, 4 ou mais de dimensões menores.

Em seção delgada foi feito um exame microscópico do contato entre as camadas de sílex e o calcário (Foto 8). Macroscopicamente o contato parece linear, embora não retilíneo, mas detalhes vistos ao microscópio mostram um avanço algo irregular do processo de silicificação parcial. No contato são mesmo observados oólitos de composição mista. Aparentemente o processo de silicificação agiu primeiramente sobre os oblitos e o cimento foi silicificado em fase posterior, pois foram vistas áreas de cimento calcítico contendo oólitos completamente silicificados nas proximidades do contato. A silicificação torna os oólitos praticamente opacos (ferruginização?) sob luz polarizada paralela ou cruzada, mas o tamanho e outras características são mais ou menos preservadas. No tocante às estruturas internas, as disposições fibro-radiadas são quase que completamente obliteradas, principalmente pela opacidade, enquanto a disposição concêntrica é ligeiramente bem mais visivel. O cimento da parte carbonática é de calcita, enquanto o da parte silicifícada é de calcedônia. 


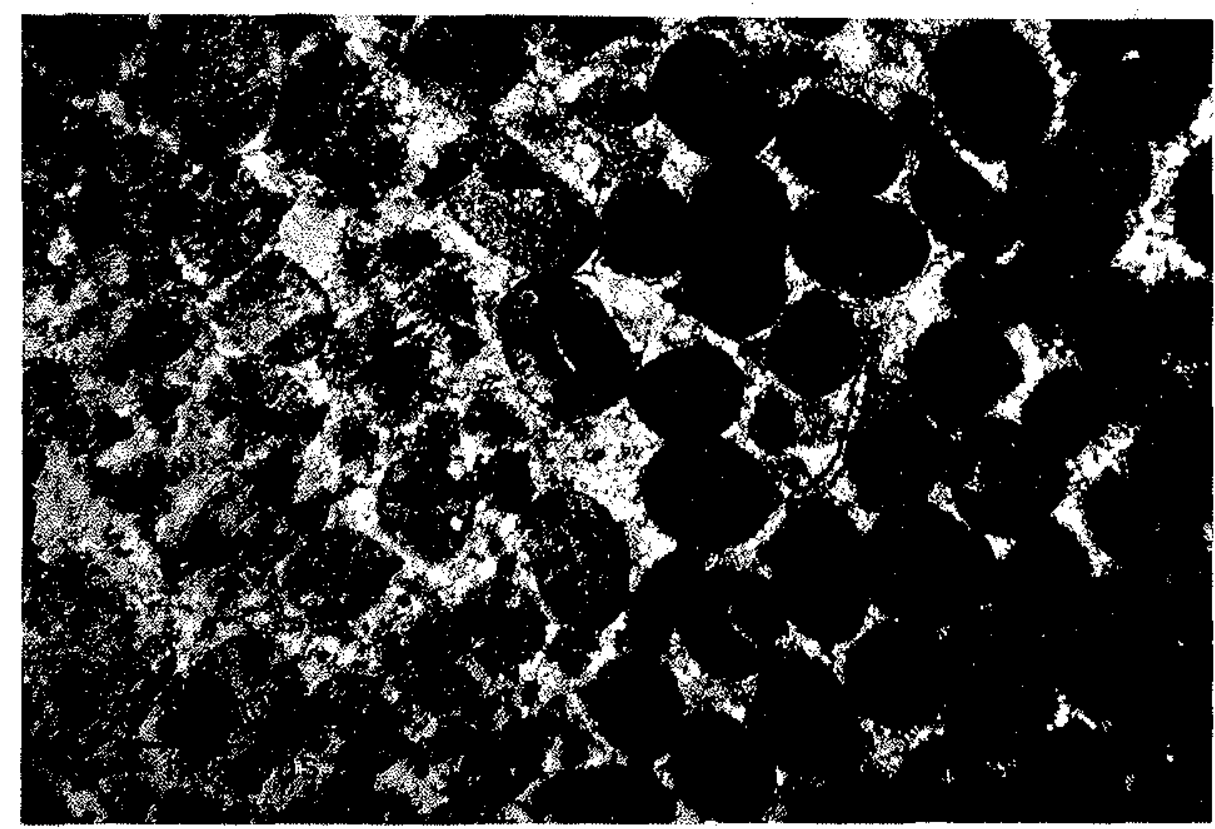

Foto 8 - Contato de camadas de sílex (oólitos opacos) com calcário (oólitos claros) (Pedreira do Pau Preto, Taguaí, SP)

Outro tipo de silicificação é de amplitude apenas microscópica, tendo sido observada em seções delgadas, em forma de pequenos núcleos de calcedônia fibrosa ou de silicificação parcial de oólitos carbonáticos. Poderiam ser processos incipientes que progrediriam até dar origem aos nódulos e camadas de sílex. Na Pedreira do Pau Preto foi visto nódulo esférico em fase inicial de formação, com sua borda inteiramente silicificada e o interior ainda constituído inteiramente de $\mathrm{CaCO}_{3}$.

Brecha sedimentar Na parte SE da Pedreira Velha foi verificada também a ocorrência de brecha sedimentar muito bem caracterizada, que seria classificada como intraformacional (Foto 9). Esta brecha não se desenvolve no calcário, mas em sedimentos argilosos carbonáticos superpostos aos bancos calcários.

A brecha é ressaltada por diferenças de coloração entre uma parte fraturada, de cor amarela, e os fragmentos de mesmo material, muito angulosos, que preenchem as fráturas. Os espaços entre as fraturas são ocupados por um sedimento de coloração rósea.

Em exame microscópico foi visto que a brecha, visualizada facilmente em exame macroscópico de campo, não é definida apenas por simples diferença de coloração mas também de constituição. A parte amarela, fraturada, é de granulação mais fina, com menos de $10 \%$ de grãos de quartzo de $0,008 \mathrm{~mm}$ a $0,020 \mathrm{~mm}$. A maior parte das partículas desta parte fina tem em torno de $0,002 \mathrm{~mm}$ de diâmetro, pouco visíveis mesmo com aumento de 80 vezes, sendo mais raramente encontrados cristais romboédricos mais bem desenvolvidos de calcita (até $0,040 \mathrm{~mm}$ ). O sedimento róseo que preenche essas fraturas é ligeiramente mais grosseiro, em cuja massa entram $15 \%$ a $20 \%$ de grãos de quartzo de $0,008 \mathrm{~mm}$ a $0,040 \mathrm{~mm}$, mas a matriz é aqui também muito fina (argila), sobressaindo freqüentes cristais romboédricos de calcita(?). Este material róseo é bastante semelhante ao do sedimento gretado. 


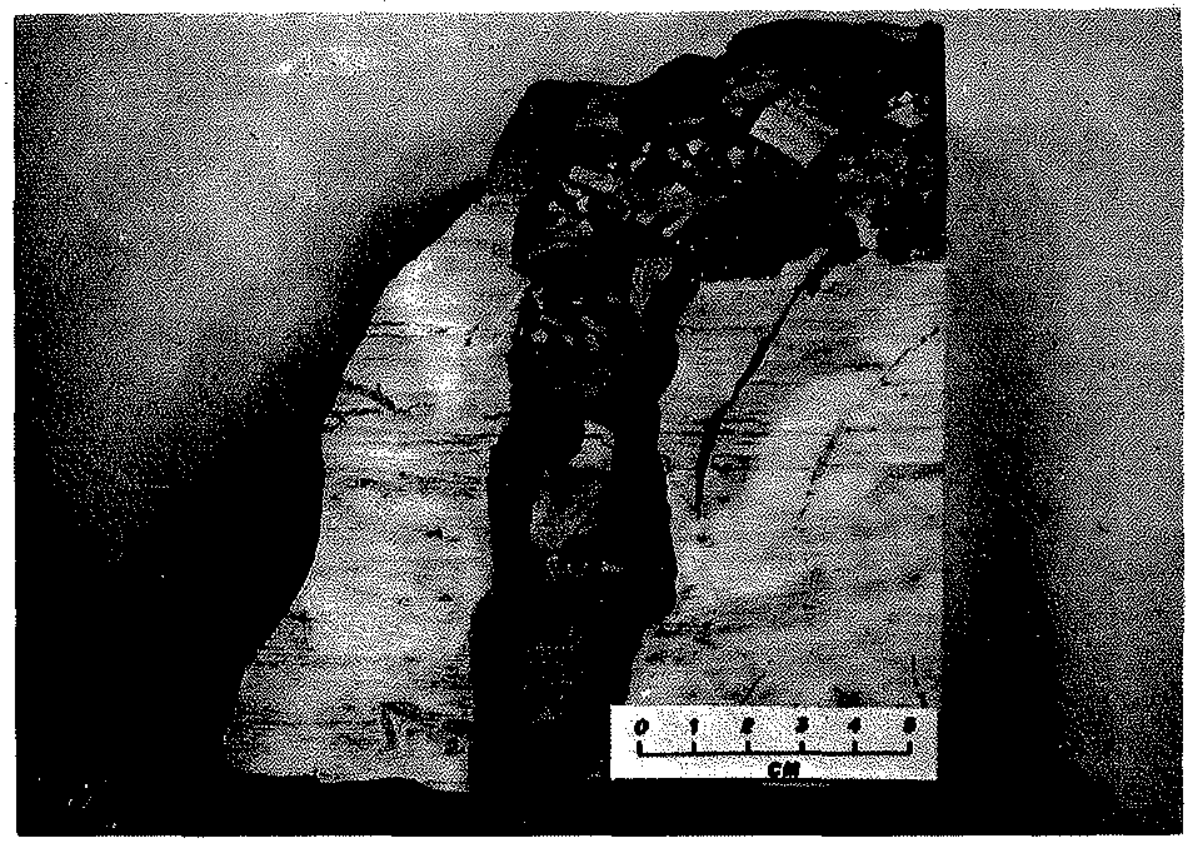

Foto 9 - Brecha sedimentar intraformacional onde são vistos fragmentos angulosos de cor mais clara (granulação mais fina) imersos em massa de cor mais escura (granulação mais grosseira) (Pedreira Velha, Taguaí, SP)

GRANULOMETRIA DOS OÓLITOS Generalidades Em virtude da composição mineralógica dos oólitos, que têm a mesma composição que o cimento, a análise granulométrica foi feita por meio de seções delgadas.

As análises foram efetuadas em 16 lâminas correspondentes a igual número de amostras, todas coletadas na Pedreira Velha da Fazenda São Vicente.

$O$ processo usado foi o de contagem em pontos (point counting), que requer a utilização de um microscópio petrográfico provido de uma ocular micrométrica e charriot, segundo a técnica descrita por Friedman em vários trabalhos (1958, 1965a, 1965b).

Quanto ao número de grãos, a maioria dos pesquisadores conta 200 a 500 grãos por lâmina. No caso em pauta, foram contados 100 grãos/lâmina, cujos resultados foram bastante representativos, levando-se em consideração a granulação muito uniforme deste material. Vale a pena registrar que a diferença na granulometria, quando se efetua a análise pelo peneiramento em relação a este processo das seções delgadas, não foi considerada.

Resultados e discussões Os resultados encontrados por este processo de análise granulométrica acham-se sumariados na Tab. I.

As próprias curvas acumulativas obtidas para a distribuição granulométrica dos oólitos mostraram o alto grau de seleção, numericamente definido pelos valores de desvio-padrão.

A partir dás curvas acumulativas foram determinados dois parametros estatísticos, que são o diâmetro médio e o desvio-padrão da distribuição de tamanhos dos oblitos. Para estes cálculos foram utilizadas as formulas simplificadas de Krumbein e Sloss (1963): 
Tabela I - Caracteristicas granulométricas de calcários ooliticos e seus produtos de silicificação (calcário oolítico da Formação Estrada Nova do Grupo Passa Dois, Permiano da Bacia do Paraná)

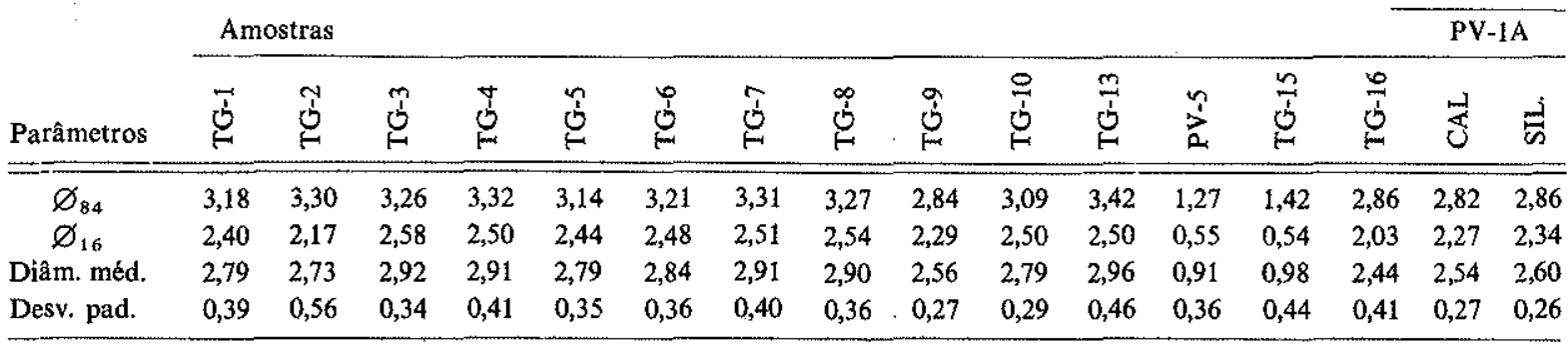

$$
\begin{aligned}
& \text { Diâmetro médio }=\frac{\left(\varnothing_{84}+\varnothing_{16}\right)}{2} \\
& \text { Desvio padrão }=\frac{\left(\varnothing_{84}-\varnothing_{16}\right)}{2}
\end{aligned}
$$

Nestas relações, $\varnothing_{16}$ e $\varnothing_{84}$ representam os diâmetros corresponuentes a $16 \%$ e $84 \%$ da distribuição granulométrica, respectivamente, extraídos a partir de curvas acumulativas construídas em papel de probabilidade aritmética (Fig. 3).

Os resultados encontrados mostram que os diametros médios mais comuns dos oólitos (carbonáticos e silicificados) variam entre máximo de $2,44 \varnothing(0,185 \mathrm{~mm})$ na amostra TG-16 até um mínimo de 2,92 $\varnothing(0,133 \mathrm{~mm})$ na amostra TG-3, intervalo este que se situa entre as "areias finas" segundo Wentworth (1922). Ainda segundo a escala granulométrica deste autor, o nível de oólitos mais grosseiros, representados pelas laminas das amostras PV-5 e TG-15, mostrou que os diâmetros variam de $0,91 \varnothing(0,535 \mathrm{~mm})$ a $0,98 \varnothing$ $(0,515 \mathrm{~mm})$, correspondentes à fração de areia grossa.

Os valores de desvio-padrão tendo sido baixos, entre um mínimo de 0,26 e um máximo de 0,56, nas amostras PV-1A e TG-2, respectivamente, indicaram graus de seleção bons. A seleção perfeita seria, neste caso, indicada pelo valor zero. Naturalmente, o grau de seleção muito alto, neste caso, não é o resultado de seleção por transporte, pois sabe-se que o transporte foi relativamente pequeno. Deve resultar da granulação bastante uniforme dos oólitos na sua própria origem.

PALEOCORRENTES DEPOSICIONAIS As paleocorrentes deposicionais podem ser deduzidas pela orientação preferencial de estruturas sedimentares singenéticas vetoriais. Entre as estruturas sedimentares, aqui encontradas, as que podem fornecer esta indicação são: estratificações cruzadas, laminação cruzada de migração de marcas onduladas e as marcas onduladas assimétricas. Destas estruturas, somente as estratificaçōes cruzadas ocorrem com freqüência suficiente que permitiu efetuar um cálculo estatístico de orientação preferencial das paleocorrentes que prevaleceram durante a deposição dos calcários.

Abrangendo as pedreiras de Pau Preto e Pedreira Velha, foram efetuadas 130 medidas de atitudes de camadas frontais de estratificações cruzadas. Destas, 100 medidas foram. obtidas na Pedreira Velha e 30 em Pau Preto.

A frente de exploração da Pedreira Velha é sinuosa e se estendia, na ocasião das medições, por mais de $400 \mathrm{~m}$. Esta frente foi dividida em duas seçб̋es de cerca de $200 \mathrm{~m}$ cada uma, e o primeiro grupo de medidas foi realizado no extremo rumo $300^{\circ}(\mathrm{NW})$ da pedreira e a segunda série de 50 medidas, no extremo rumo $120^{\circ}$ (SE). 


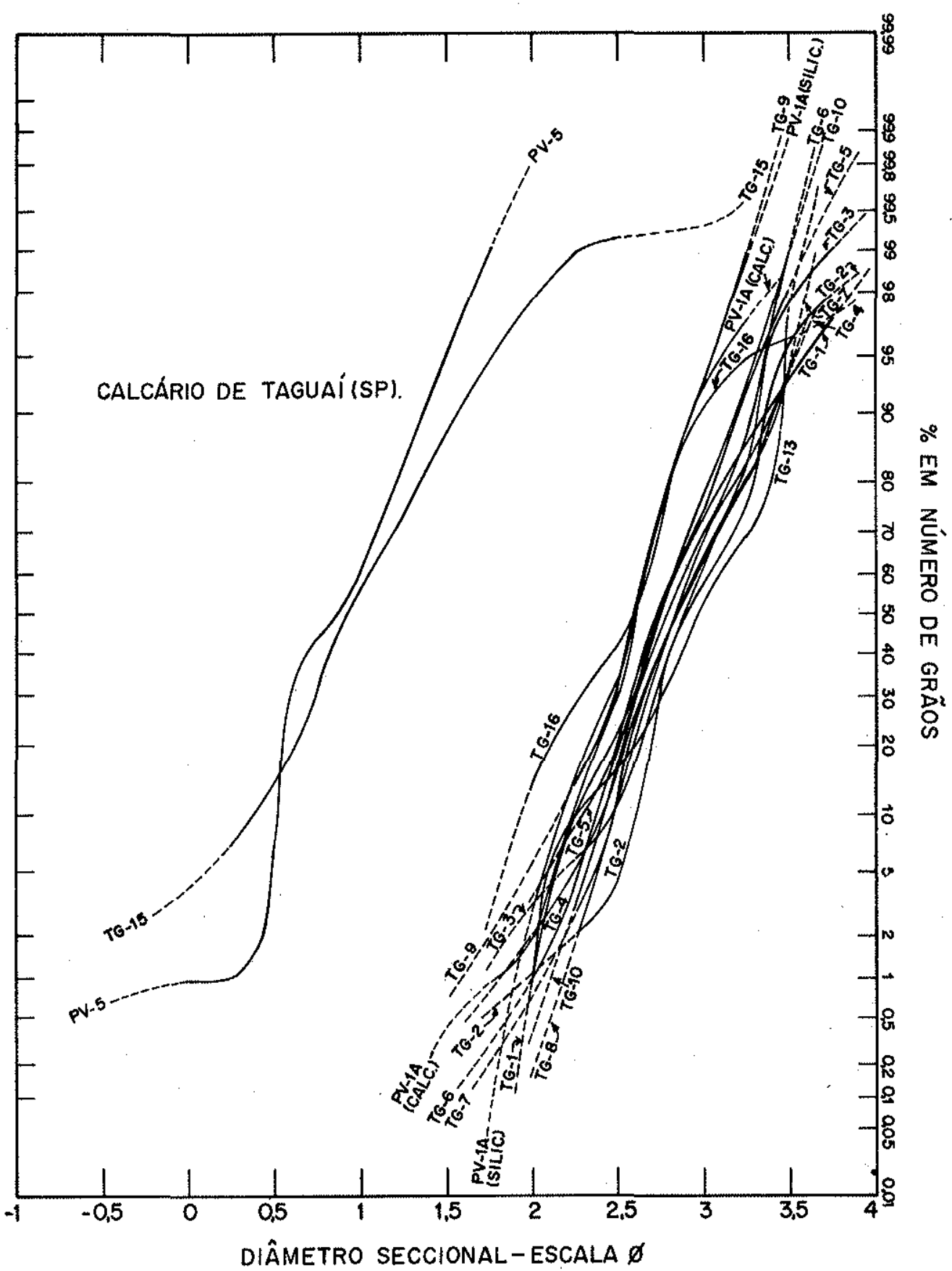

Figura 3 - Características de granulometria de calcários oolíticos e seus produtos de silicificação (calcário de Taguaí, SP)

Os três grupos de medidas foram trabalhados estatisticamente, reunindo-se dentro de cada grupo em classes de $10^{\circ}$. Em seguida foram construídos histogramas circulares de frequiência numérica segundo as classes (Fig. 4). 
$O$ vetor médio final para cada grupo de medidas foi encontrado pelo processo de Pincus (1956). Os resultados indicaram fatores de consistência relativamente baixos, o que demonstra variabilidade considerável das paleocorrentes. No entanto, os vetores médios encontrados para os 3 grupos de medidas foram: $159^{\circ}$ (S 21 $1^{\circ} \mathrm{E}$ ) no extremo SE e $146^{\circ}\left(\mathrm{S} 34^{\circ} \mathrm{E}\right)$ no extremo NW da Pedreira Velha, e $117^{\circ}\left(\mathrm{S} 67^{\circ}\right.$ E) na Pedreira do Pau Preto.

A média vetorial bastante consistente, sempre dirigida para o quadrante SE, sugere que a orientação das paleocorrentes, embora relativamente variável, foi dirigida predo-

\section{PEDREIRA PAU PRETO}

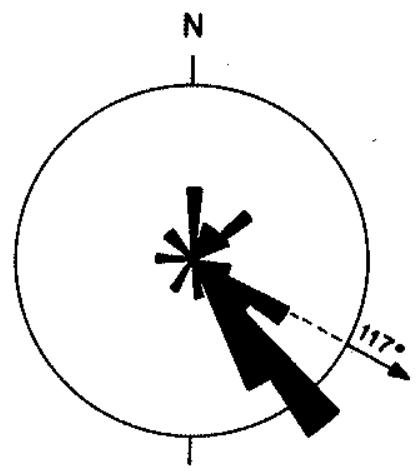

NÚMERO OE MEDIOAS * 30 RUMO MÉDIO $=117^{\circ}\left(363^{\circ} E\right)$ FATOR DE CONSISTENCIA $=0,47$ MERGULHO MÁXIMO $22^{\circ}$ MERGULHO $M$ EED $10=15^{\circ}$ MERGULHO MINIMO $=5^{\circ}$

\section{PEDREIRA VELHA}

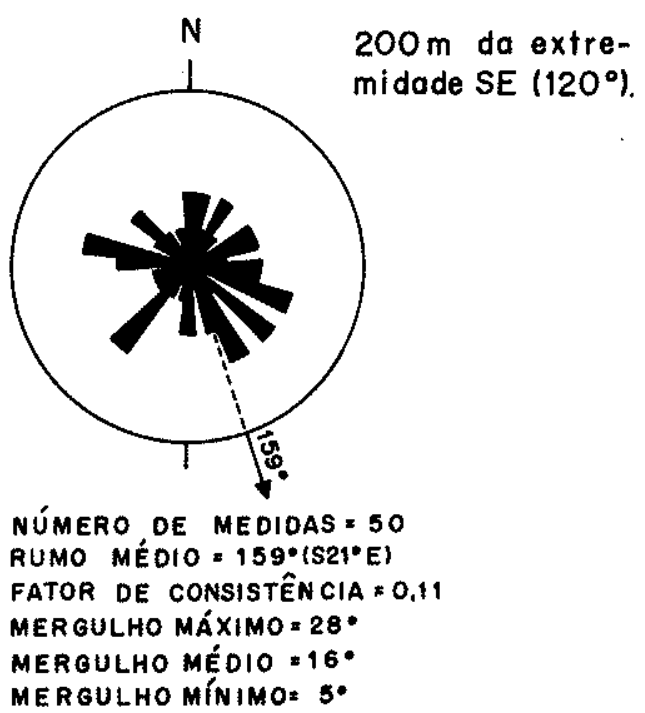

PEDREIRA VELHA

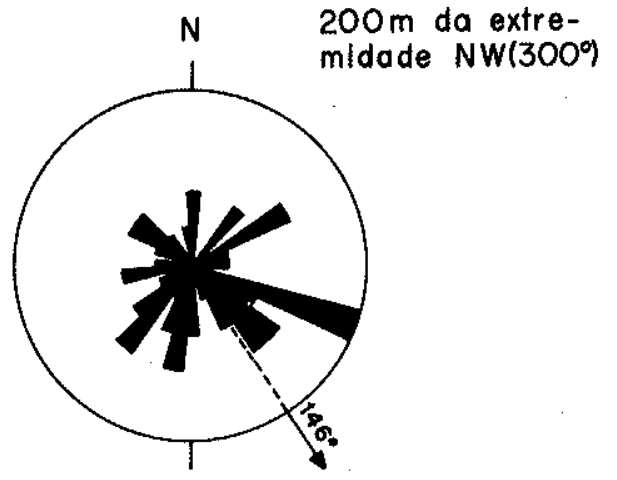

NÚMERO DE MEOIDAS $: 50$

RUMO MÉDIO $146^{\circ}\left(S 34^{\circ} E\right)$

FATOR DE CONSISTÊNCIA 00,17

MERGULHO MÁXIMO = $22^{\circ}$

MERGULHO MÉDIO $=15^{\circ}$

MERGULHO MINIMO = 5*

Figura 4 - Histogramas circulares de atitudes de camadas frontais de estratos cruzados em calcários oolíticos [Formação Estrada Nova (Taguaí, SP)] 
minantemente para aquele quadrante, pelo menos durante a deposição das camadas de calcários da região estudada. Por outro lado, não se sobressaíram as classes situadas a $180^{\circ}$ do rumo do vetor médio, fato que, se presente, seria sugestivo de padrão comum em regiões de praias.

GOMPOSIÇÃO MINERALÓGICA Na composição mineralógica predomina a calcita, já identificada por microscopia óptica e discutida anteriormente, em forma de ob́litos. Outros componentes de origem detrítica possuem predominantemente granulação síltico-argilosa (diâmetró inferior a $0,062 \mathrm{~mm}$ ), como mostraram os resultados de estudos de resíduos insolúveis ao ácido clorídrico diluído (20\% em volume) (Tab. II).

Quanto ao conteúdo em resíduos solúveis e insolúveis ao ácido clorídrico foram analisadas 22 amostras de sedimentos carbonáticos. A amostra TG-14 não é de calcário mas de argilito carbonático com gretás de contração gigantescas.

Conforme os grupos de amostras submetidas a esta análise foram obtidos os seguintes resultados:

a) 12 amostras coletadas na frente de exploração da Pedreira Velha (série TG) mostraram-se completamente isentas de resíduos insolúveis maiores que $0,062 \mathrm{~mm}$ de diâmetro, e todas exibiram relação $\mathrm{CaCO}_{3}(\%) / \mathrm{MgCO}_{3}(\%) \geqslant 10$, conforme mostraram os resultados de análises de composição química, e porcentagem de não-carbonatos inferior a $8 \%$, que

Tabela II - Composição em resíduos solúveis e insolúveis em ácido cloridrico diluído dos calcários de Taguaí (SP)

\begin{tabular}{|c|c|c|c|c|}
\hline \multirow{2}{*}{ Amostra } & \multirow{2}{*}{ Solúveis } & \multicolumn{2}{|c|}{ Insolúveis } & \multirow{2}{*}{ Classificação } \\
\hline & & $<0,062 \mathrm{~mm}$ & $>0,062 \mathrm{~mm}$ & \\
\hline TG-1 & $92,76 \%$ & $7,24 \%$ & $0 \%$ & Calcário quase puro \\
\hline TG-2 & 95,24 & 4,76 & 0 & Calcário quase puro \\
\hline TG-3 & 93,56 & 6,44 & 0 & Calcário quase puro \\
\hline TG-4 & 92,80 & 7,20 & 0 & Calcário quase puro \\
\hline TG-5 & 93,00 & 7,00 & 0 & Calcário quase puro \\
\hline TG-6 & 93,56 & 6,44 & 0 & Calcário quase puro \\
\hline TG-7 & 97,12 & 2,88 & 0 & Calcário quase puro \\
\hline TG-8 & 97,20 & 2,80 & 0 & Calcário quase puro \\
\hline TG-9 & 94,40 & 5,60 & 0 & Calcário quase puro \\
\hline TG-10 & 95,44 & 4,56 & 0 & Calcário quase puro \\
\hline TG-11 & 95,16 & 4,84 & 0 & Calcário puro \\
\hline TG-13 & 92,40 & 7,60 & 0 & Calcário puro \\
\hline TG-14 & 27,08 & 51,68 & 21,24 & Argilito carbonático \\
\hline PP-1 & 70,90 & 29,10 & 0 & Calcário silicoso \\
\hline PP-2 & 84,16 & 15,84 & 0 & Calcário silicoso \\
\hline PP-3 & 87,00 & 13,00 & 0 & Calcário silicoso \\
\hline PP-4 & 86,60 & 13,40 & 0 & Calcário silicoso \\
\hline PP-5 & 98,30 & 1,70 & 0 & Calcário quase puro \\
\hline$P V-1 B$ & 86,25 & 15,75 & 0 & Calcário silicoso \\
\hline PV-2 & 94,05 & 5,95 & 0 & Calcário silicoso \\
\hline PV-3 & 73,20 & 1,25 & 25,25 & Calcário silicoso \\
\hline PV-4 & 92,00 & 8,00 & 0 & Calcário silicoso \\
\hline
\end{tabular}


permite'sejam classificados quimicamente como calcários quase puros, segundo o esquema proposto por Guimarães (1952) e modificado para ser usado neste trabalho;

b) 5 amostras dispersas coletadas na Pedreira do Pau Preto (série PP) mostraram-se todas isentas de insolúveis maiores que $0,062 \mathrm{~mm}$ de diâmetro, mas a porcentagem de não-carbonatos (insolúveis) foi superior a $8 \% \mathrm{em} 4$ das amostras, que seriam então classificados como calcários silicosos, segundo o autor supracitado, e uma somente foi de calcário quase puro (não-carbonatos inferior a $8 \%$ ); e

c) as amostras PV-1B a PV-4, coletadas em uma sequiência vertical de calcários oolíticos da Pedreira Velha, mostraram maior variabilidade. A amostra PV-3 mostrou-se muito rica em resíduos insolúveis arenosos (maior que $0,062 \mathrm{~mm}$ ) e todas podem ser enquadradas como calcários silicosos.

Os resíduos insolúveis arenosos encontrados aqui são constituídos principalmente de grãos de quartzo detrítico. Os nódulos e camadas de sílex não participam daquela fração, já que estes foram evitados durante a amostragem, pois representam fenômenos epigenéticos e, portanto, sem relação direta com a composição original do calcário.

Os resíduos insolúveis síltico-argilosos são constituídos na maior parte por minerais de argila, mas naturalmente com participação de menor quantidade de quartzo e outros minerais detríticos. Os minerais de argila foram identificados, em caráter de reconhecimento preliminar, por processo de difração de raios $\mathrm{X}$, tendo sido analisadas 19 amostras (TG-1 a TG-9, TG-11, TG-12, TG-14, PP-1 a PP-4 e PV-2 a PV-4). Foram determinados 6 tipos diferentes de minerais de argila: atapulgita, caolinita, clorita, illita, montmorillonita e sepiolita. Devido ao caráter preliminar dessas identificações, as amostras foram analisadas sem tratamentos térmicos auxiliares de identificação ou submetidas à ação de outros reagentes, a não ser o etilenoglicol, de modo que a atapulgita e sepiolita, principalmente, carecem de determinação mais definitiva.

COMPOSIÇÃO QUIMICA Composições químicas das amostras de calcários toram determinadas quanto aos elementos maiores, menores e traços. Todas estas análises foram executadas por fluorescência de raios $\mathrm{X}$ no aparelho marca Philips pertencente ao Centro de Pesquisas Geocronológicas do Instituto de Geociências da Universidade de São Paulo.

Elementos maiores e menores Os elementos maiores e menores foram determinados em 22 amostras de sedimentos. Por não haver padrőes adequados, e em virtude da variação dos teores dos elementos nas diversas amostras, foram analisadas algumas amostras por via química, e com os resultados foram construídas curvas-padrão para cada um dos seguintes elementos: $\mathrm{Fe}, \mathrm{Mn}, \mathrm{Ti}, \mathrm{Ca}, \mathrm{Al}, \mathrm{Si}$ e $\mathrm{Mg}$. Para o $\mathrm{K}$ foi utilizado como padrão uma amostra contendo $0,25 \%$ de $\mathrm{K}_{2} \mathrm{O}$ previamente analisada por fotometria de chama. As análises por via química foram realizadas pelos métodos convencionais.

A composição em elementos maiores e menores nas amostras analisadas encontra-se na Tab. III. De um modo geral, os teores não apresentam grandes variaç⿸̃es, mas somente a amostra TG-14 deu resultados bem discrepantes das restantes. Isto se deve à sua proveniência, pois não é um calcário oolítico, mas sim argilito carbònático gretado. A amostra TG-13, que representa o material de preenchimento dessas gretas, apresentou composição química ligeiramente diferente dos calcários de uma maneira geral, pois o teor de $\mathrm{CaO}$ foi menor em favor de teor maior de $\mathrm{SiO}_{2}$, que se deve a maior participação de fração argilosa entre os seus resíduos insolúveis.

$\mathrm{Na}$ Tab. IV têm-se os valores máximos, médios e mínimos para os elementos analisados. Exceto a amostra TG-14, todas mostraram composiçăo química de calcários de elevada pureza. Além disso, o teor bastante baixo de $\mathrm{MgO}$ mostra que o calcário é bem pouco dolomítico. 
Tabela III - Composição em elementos maiores e menores dos calcários oolíticos (calcário da Formação Estrada Nova, Fazenda São Vicente, Taguaí, SP)

\begin{tabular}{llllllllll}
\hline Amostras & P. Fogo & $\mathrm{Fe}_{2} \mathrm{O}_{3}$ & $\mathrm{MnO}$ & $\mathrm{TiO}_{2}$ & $\mathrm{MgO}$ & $\mathrm{CaO}$ & $\mathrm{K}_{2} \mathrm{O}$ & $\mathrm{SiO}_{2}$ & $\mathrm{Al}_{2} \mathrm{O}_{3}$ \\
\hline PV-1B & $39,18 \%$ & $0,26 \%$ & $0,04 \%$ & $0,09 \%$ & $0,48 \%$ & $44,74 \%$ & $0,24 \%$ & $13,81 \%$ & $1,19 \%$ \\
PV-2 & 41,77 & 0,44 & 0,04 & 0,09 & 0,60 & 48,05 & 0,26 & 7,36 & 1,29 \\
PV-3 & 42,18 & 0,28 & 0,05 & 0,08 & 0,74 & 49,86 & 0,26 & 5,36 & 1,13 \\
PV-4 & 41,74 & 0,40 & 0,07 & 0,09 & 2,44 & 47,72 & 0,41 & 5,09 & 1,23 \\
PP-2 & 39,27 & 0,47 & 0,08 & 0,10 & 0,53 & 47,80 & 0,35 & 9,70 & 1,52 \\
PP-3 & 41,18 & 0,47 & 0,06 & 0,10 & 0,36 & 48,63 & 0,31 & 7,25 & 1,38 \\
PP-4 & 41,81 & 0,40 & 0,06 & 0,08 & 0,18 & 49,87 & 0,18 & 6,11 & 0,70 \\
PP-5 & 41,88 & 0,29 & 0,06 & 0,08 & 0,75 & 50,94 & 0,15 & 4,08 & 0,62 \\
TG-1 & 41,41 & 0,33 & 0,05 & 0,09 & 0,42 & 48,64 & 0,31 & 7,31 & 1,26 \\
TG-2 & 43,13 & 0,32 & 0,05 & 0,09 & 2,37 & 47,62 & 0,49 & 4,18 & 1,34 \\
TG-3 & 42,01 & 0,32 & 0,05 & 0,09 & 1,01 & 48,95 & 0,37 & 5,38 & 1,20 \\
TG-4 & 41,19 & 0,47 & 0,05 & 0,09 & 2,65 & 47,69 & 0,42 & 6,39 & 1,38 \\
TG-5 & 40,14 & 0,56 & 0,06 & 0,11 & 2,83 & 46,96 & 0,64 & 7,13 & 1,79 \\
TG-6 & 40,86 & 0,44 & 0,06 & 0,10 & 2,50 & 46,94 & 0,40 & 7,20 & 1,52 \\
TG-7 & 42,05 & 0,37 & 0,05 & 0,09 & 1,56 & 49,11 & 0,22 & 5,31 & 0,99 \\
TG-8 & 43,28 & 0,45 & 0,07 & 0,08 & 1,07 & 49,43 & 0,24 & 4,43 & 1,01 \\
TG-9 & 42,00 & 0,36 & 0,05 & 0,09 & 0,22 & 48,83 & 0,27 & 5,81 & 1,27 \\
TG-10 & 42,99 & 0,31 & 0,05 & 0,09 & 1,12 & 48,06 & 0,18 & 6,30 & 0,74 \\
TG-11 & 42,17 & 0,35 & 0,06 & 0,08 & 0,21 & 51,83 & 0,24 & 3,53 & 0,89 \\
TG-12 & 40,53 & 0,50 & 0,07 & 0,09 & 0,85 & 48,42 & 0,32 & 6,98 & 1,33 \\
TG-13 & 37,40 & 0,50 & 0,05 & 0,10 & 2,43 & 41,40 & 0,45 & 15,52 & 2,84 \\
TG-14 & 17,35 & 3,06 & 0,07 & 0,42 & 4,80 & 9,36 & 0,37 & 48,94 & 16,42 \\
\hline
\end{tabular}

Elementos-traģos. Os elementos-traços foram também analisados por fluorescência de raios $\mathrm{X}$, tendo sido utilizados como padróes as amostras W-1, GSP-1, BCR-1, AGV-1, PGG-1 e DTS-1, padrões internacionais do USGS (United States Geological Survey). Devido. à variação da matriz entre as diferentes amostras, foram feitas correções utilizando-se a linha de base (background) (Fairbairn e Hurley, 1970), radiação Compton $\mathrm{K} \alpha$ do tubo de Mo (Reynolds, 1963) e radiação $\mathbf{K} \alpha$ do tubo de $\mathbf{W}$.

Em 23 amostras, das quais 22 são de calcários, foram feitas dosagens de 10 tipos diferentes de elementos-traços (Tab. IV). Desses elementos sobressaem os teores, em geral menores, do $\mathrm{Zn}, \mathrm{Zr}$ e Ba, quando confrontados com os resultados encontrados por Suguio (1973: 179-181) nos calcários continentais da Formação Bauru. Infelizmente, o teor de $B$, que no caso de sedimentos argilosos é freqüentemente tomado como indice de ambiente marinho, não foi possível de ser analisado. Por outro lado, os teores de Rb e Ga, que nos folhelhos poderiam indicar também os ambientes de sedimentação, foram sensivelmente mais baixos que nos calcários da Formação Bauru, fato que poderia ser sugestivo de ambiente de água salgada para os calcários aqui estudados.

$\mathrm{Na}$ Tab. $\mathrm{V}$ têm-se os valores máximos, médios e mínimos para os elementos analisados. A amplitude de variação dos teores dos elementos-traços é bastante aumentada pela amostra TG-14, como aconteceu com os elementos maiores e menores.

COMPOSIÇÃO ISOTÓPICA DE CARBONO E OXIGENIO Generalidades Composições isotópicas de carbonatos em oxigênio e carbono têm sido usadas para distinguir 
Tabela IV - Composição em elementos-traços dos calcários oolíticos (unidade p.p.m.) (calcário

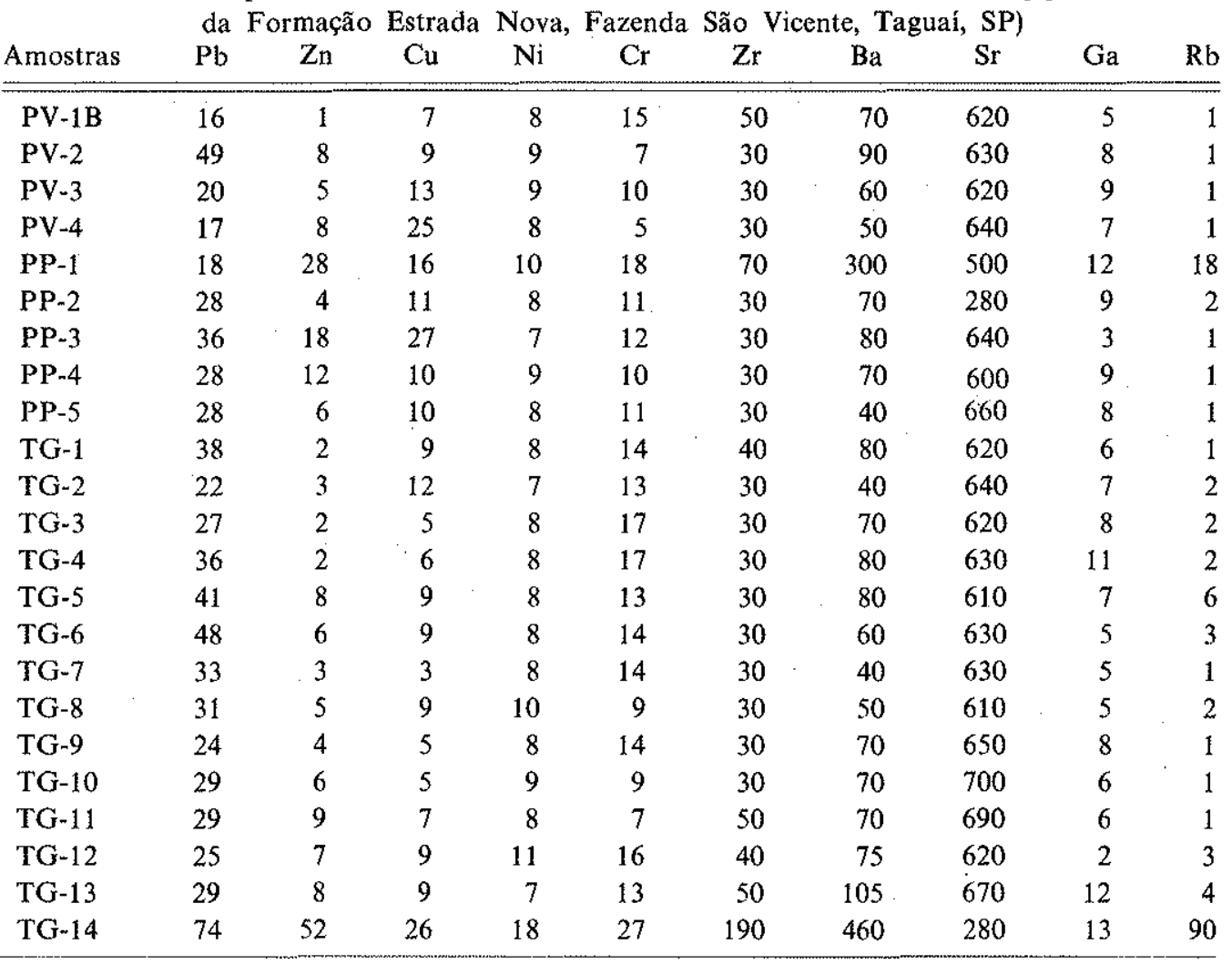

Tabela V - Composição em elementos maiores, menores e traços (teores máximo, médio e minimo) dos calcários oolíticos da Formação Estrada Nova (Taguai, SP)

\begin{tabular}{lrrr|rrrrr}
\hline \multicolumn{3}{c}{ Elementos maiores e menores $(\%)$} & \multicolumn{3}{c}{ Elementos-traços (p.p.m.) } \\
\hline Elemento & Máximo & Médio & Mínimo & Elemento & Máximo & Médio & Mínimo \\
\hline $\mathrm{P.} \mathrm{Fogo}$ & 43,28 & 40,25 & 17,35 & $\mathrm{~Pb}$ & 74 & 31 & 16 \\
$\mathrm{Fe}_{2} \mathrm{O}_{3}$ & 3,06 & 0,51 & 0,26 & $\mathrm{Zn}$ & 52 & 9 & 1 \\
$\mathrm{MnO}$ & 0,08 & 0,06 & 0,04 & $\mathrm{Cu}$ & 26 & 11 & 3 \\
$\mathrm{TiO}_{2}$ & 0,42 & 0,10 & 0,08 & $\mathrm{Ni}$ & 18 & 9 & 7 \\
$\mathrm{MgO}$ & 4,80 & 1,37 & 0,18 & $\mathrm{Cr}$ & 27 & 13 & 5 \\
$\mathrm{CaO}$ & 51,83 & 46,40 & 9,36 & $\mathrm{Zr}$ & 190 & 42 & 30 \\
$\mathrm{~K}_{2} \mathrm{O}$ & 0,64 & 0,32 & 0,15 & $\mathrm{Ba}$ & 460 & 95 & 40 \\
$\mathrm{SiO}_{2}$ & 48,94 & 8,78 & 3,53 & $\mathrm{Sr}$ & 700 & 599 & 280 \\
$\mathrm{Al}_{2} \mathrm{O}_{3}$ & 16,42 & 1,96 & 0,62 & $\mathrm{Ga}$ & 13 & 7 & 2 \\
& & & & $\mathrm{Rb}$ & 90 & 6 & 1 \\
\hline
\end{tabular}

entre os calcários depositados em ambiente marinho e em água doce. Trabalhos prévios do gênero realizados em sedimentos da Bacia do Paraná são aqueles de autoria de De Giovani e outros (1972) e de Suguio (1973), desenvolvidos com calcários da Formação Irati e da Formação Bauru, respectivamente. 
Keith e Weber (1964), após estudo minucioso de calcários de várias procedências conhecidas, estabeleceram um limite arbitrário de $-2,00 \%$ de $\delta \mathrm{C}^{13}$ para diferenciar calcários depositados em ambiente marinho e água doce. Este limite foi estipulado em função dos resultados encontrados em calcários dessas origens, já previamente conhecidas.

A composição isotópica de oxigênio também pode fornecer informaçzes sobre o ambiente geológico de sedimentação. Sabe-se que as águas meteóricas apresentam valores de $\delta \mathrm{O}^{18}$ menores que a média dos oceanos, enquanto águas que sofrem intensa evaporação tendem a ser isotopicamente enriquecidas, isto é, mostram incremento de $\delta \mathrm{O}^{18}$. Como o $\mathrm{CO}_{2}$, que é dissolvido na água, antes de precipitar na forma de carbonato fica em equilíbrio isotópico com a água, e a composição isotópica $\left(\delta \mathrm{O}^{18}\right)$ do calcário assim formado dependerá da concentração de $\mathrm{O}^{18}$ da água.

Método de análise As amostras de calcários foram inicialmente britadas até atingir dimensões de fragmentos de $0,50 \mathrm{~cm}$ e, em seguida, moídas e passadas pela peneira de 100 meshes $(0,149 \mathrm{~mm})$.

A decomposição química dessas amostras, com a finalidade de extrair o díxido de carbono para análise isotópica do oxigênio e do carbono, foi efetuada pelo método comumente adotado, por intermédio de ácido fosfórico a $100 \%$ a temperatura de $25^{\circ} \mathrm{C}$ (McCrea; 1950).

O dióxido de carbono liberado pelas amostras foi analisado para massas 44, 45 e 46 em um espectrômetro de massa, Varian Mat, modelo CH-4, pertencente ao CENA (Centro de Energia Nuclear na Agricultura, Piracicaba, SP).

Para a maioria das amostras foram feitas duas medidas e as composiçóes isotópicas foram expressas em termos de $\delta$, tomando-se como padrão o PDB, segundo a fórmula:

$$
\begin{gathered}
\delta=\frac{\mathrm{R} \text { (amostra) }-\mathrm{R} \text { (padrão) }}{\mathrm{R}(\text { padrão) }} \times 1000 \\
\text { onde } \mathrm{R}=\mathrm{C}^{13} / \mathrm{C}^{12} \text { ou } \mathrm{O}^{18} / \mathrm{O}^{16}
\end{gathered}
$$

Sobre as médias encontradas, como resultado de duas medidas, foram aplicadas as correções para a influência de $\mathrm{O}^{17}$ sobre $\delta \mathrm{C}^{13}$ e para a influência de $\mathrm{G}^{13}$ sobre $\delta \mathrm{O}^{18}$. Nessas correções foram adotadas as equações de CRAIG (1957):

$$
\begin{aligned}
& \delta \mathrm{C}^{13}=1,0676 \delta_{m}-0,0338 \delta \mathrm{O}^{18} \\
& \delta \mathrm{O}^{18}=1,0014 \delta_{m}-0,009 \quad \delta \mathrm{C}^{13}
\end{aligned}
$$

Material analisado e discussão dos resultados Foram analisadas 10 amostras de calcários da Formação Estrada Nova, provenientes da Pedreira Velha (Taguaí).

Os resultados dessas determinações podem ser vistos na Tab. VI. Aqui estão relacionados também 10 outras amostras de calcários tipicamente continentais da Formação Bauru (Cretáceo Superior da Bacia do Paraná).

$\mathrm{O}$ confronto dos resultados permite visualizar prontamente as diferenças marcantes entre as 10 amostras da Formação Estrada Nova de um lado e as 10 amostras da Formação Bauru do outro lado. Tanto os valores de $\delta \mathrm{C}^{13}$ quanto os de $\delta \mathrm{O}^{18}$ apresentam sinais positivos, portanto valores relativos maiores, no primeiro grupo, enquanto no segundo conjunto são todos negativos.

O significado dessas diferenças de resultados é enfatizado quando se lançam os dados dos conjuntos de medidas em um gráfico $\delta \mathrm{O}^{18} \times \delta \mathrm{C}^{13}$ com indicação de ambientes de sedimentação segundo Keith e Weber (op. cit.) (Fig. 5). As amostras da Formação Estrada Nova distribuem-se em torno de $\mathrm{C}^{13} \cong+2,00 \%$, valor este indicativo de ambiente 
Tabela VI - Composição isotópica em $\delta \mathrm{C}^{13}$ e $\delta \mathrm{O}^{18}$ de calcários da Formaçào Estrada Nova (Permiano) e Formação Bauru (Cretáceo) da Bacia do Paraná

\begin{tabular}{|c|c|c|c|c|}
\hline Amostra & Tipo de rocha & Local de coleta & $\delta \mathrm{C}^{13}(\%)$ & $\delta \mathrm{O}^{18}(\%)$ \\
\hline TG-1(1) & Oolítico nít. & Pedr. Velha & $+2,45$ & $+2,82$ \\
\hline TG-2(2) & Oolítico obl. & Pedr. Velha & $+2,69$ & $+3,70$ \\
\hline TG-3(3) & Oolitico nit. & Pedr. Velha & $+1,96$ & $+2,85$ \\
\hline$T G-5(4)$ & Oolítico obl. & Pedr. Velha & $+2,15$ & $+1,87$ \\
\hline TG-8(5) & Oolítico nít. & Pedr. Velha & $+1,99$ & $+1,07$ \\
\hline TG-10(6) & Oolítico obl. & Pedr. Velha & $+2,52$ & $+2,32$ \\
\hline PP-5(7) & Oolítico & Pedr. P. Preto & $+1,93$ & $+2,33$ \\
\hline PV-1(8) & Oolítico obl. & Pedr. Velha & $+2,55$ & $+0,79$ \\
\hline PV-2(9) & Oolitico & Pedr. Velha & $+1,97$ & $+1,69$ \\
\hline PV $-3(10)$ & Oolítico & Pedr. Velha & $+1,98$ & $+1,45$ \\
\hline $78(11)$ & Conglomerát. & SC-7(BR-050) & $-9,27$ & $-6,10$ \\
\hline $113(12)$ & Brechóide & BR-262:CCPPA & $-9,10$ & $-6,67$ \\
\hline $114(13)$ & Nodular & BR-262:CCPPA & $-9,77$ & $-6,69$ \\
\hline $124(14)$ & Globular & Pedr. 2(CCPPA) & $-10,32$ & $-6,62$ \\
\hline $125(15)$ & Globular & Pedr. 2(CCPPA) & $-8,89$ & $-5,91$ \\
\hline $228(16)$ & Arenoso & Piratininga (SP) & $-7,88$ & $-5,29$ \\
\hline $231(17)$ & Nodular & $\begin{array}{l}\text { Mo. Serraria } \\
\text { Agudos (SP) }\end{array}$ & $-7,63$ & $-5,18$ \\
\hline $235(18)$ & Nodular & $\begin{array}{l}\text { Mo. São joão } \\
\text { Agudos (SP) }\end{array}$ & $-7,73$ & $-5,73$ \\
\hline $239(19)$ & Cristalino & $\begin{array}{l}\text { Faz. S. José } \\
\text { Borebi (SP) }\end{array}$ & $-7,34$ & $-4,90$ \\
\hline $240(20)$ & Nodular & $\begin{array}{l}\text { Faz. S. José } \\
\text { Borebi (SP) }\end{array}$ & $-8,49$ & $-6,32$ \\
\hline
\end{tabular}

Observação: Amostras (1) a (10) = Formação Estrada Nova; amostras (11) a (20) = Formação Bauru

marinho ou lacustre de água salgada, enquanto as amostras da Formação Bauru se situam entre $-7,00 \mathrm{a}-10,00 \%$, distanciando-se bastante do grupo 1 , com valores típicos de ambiente de água doce. Além disso, as amostras da Formação Estrada Nova apresentam valores muito altos de $\delta \mathrm{O}^{18}$, com todos os pontos possuindo valores superiores a $+0,50 \%$, atingindo inclusive valores próximos de $+4,00 \%$, fato que denota meio de intensa evaporação.

CONCLUSOES GERAIS As seguintes considerações podem ser feitas como conclusão do presente estudo:

a) O calcário oolítico, encontrado em Taguaí (SP), encerra muitas informações sobre a história geológica de sedimentação da Formação Estrada Nova na área.

b) A grande profusão de estruturas sedimentares primárias do tipo de estratificações cruzadas, laminação cruzada de marcas onduladas e marcas onduladas, as duas últimas mais raras, e a própria natureza oolítica deste sedimento aloquímico indicam um ambiente de alta energia durante a deposição dos calcários.

c) As enormes gretas de contração e a existência das estruturas supramencionadas sugerem um ambiente de águas rasas, onde os sedimentos eram freqüentemente expostos às condições aéreas, sofrendo conseqüente ressecação. 


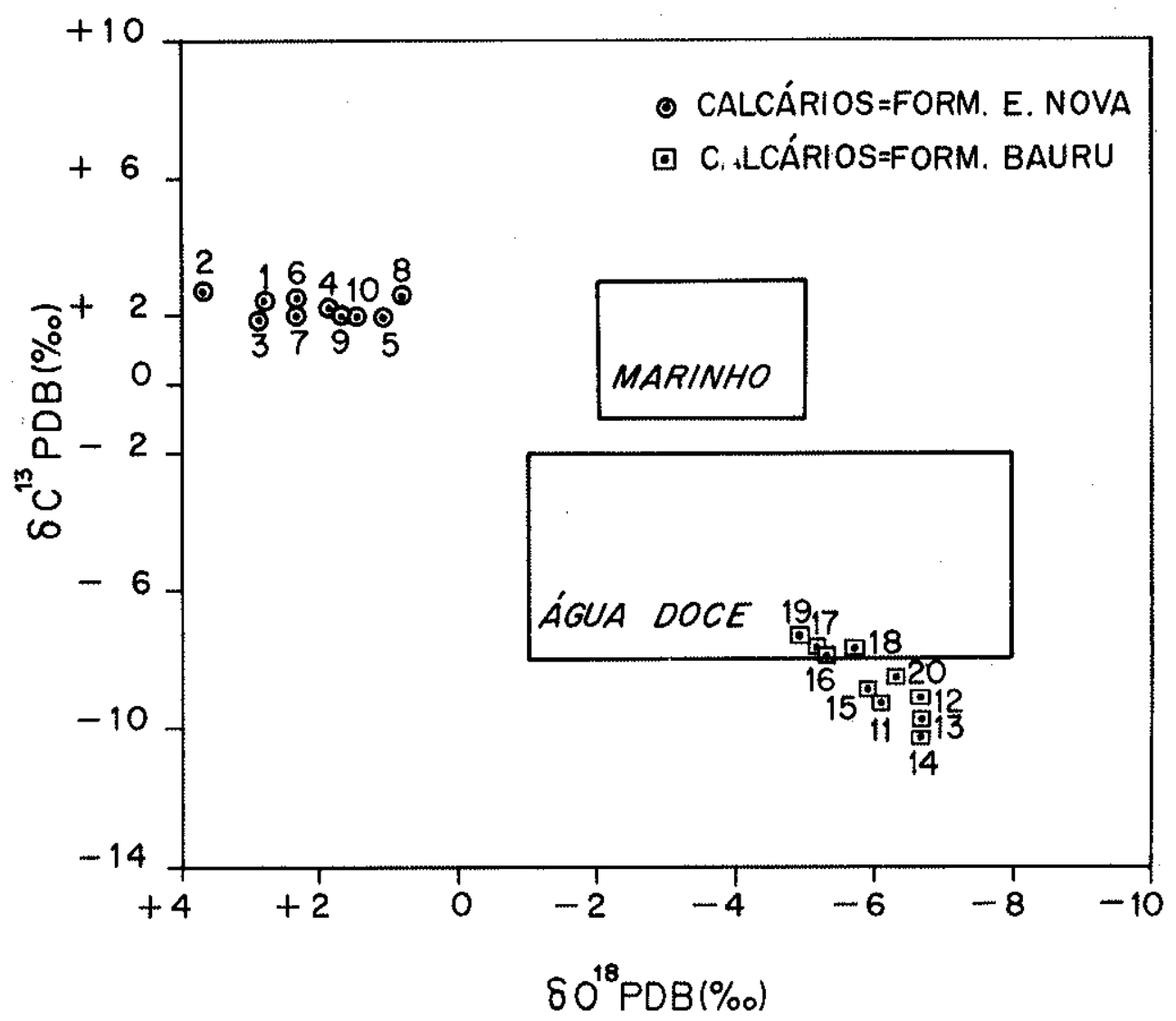

Figura 5 - Distribuição de valores de $\delta \mathrm{C}^{13} \times \delta \mathrm{O}^{18}$ para amostras da Formação Estrada Nova em confronto com as da Formação Bauru segundo o gráfico de Keith e Weber (1964)

d) As paleocorrentes que prevaleceram durante a sedimentação dos calcários oolíticos, conforme medidas de estratificações cruzadas, eram dirigidas principalmente para SE.

e) Fenômenos de silicificação (nódulos e camadas de sílex, núcleos microscópicos de calcedônia), presença de microestilólitos e ferruginização, apesar de não fornecerem indicações sobre o meio deposicional, retratam os processos pós-deposicionais pelos quais a rocha tem passado.

f) A composição mineralógica dos resíduos insolúveis (raridade de partículas maiores que $0,062 \mathrm{~mm}$ ) e a constituição química dos calcários fazem pensar na pequena disponibilidade de sedimentos mais grosseiros que siltes e argilas durante a sedimentação dos calcários. As constituições química e mineralógica sugerem que o teor em $\mathrm{SiO}_{2}$. desses calcários esteja talvez ligado principalmente aos minerais de argila.

g) Estratificações cruzadas de ângulo baixo (menor que $20^{\circ}$ ), marcas onduladas de índices de retilinidade relativamente altos (maior que 9), teor relativamente baixo em alguns elementos-traços mais comuns em ambiente de água doce ( $\mathrm{Ga}$ e $\mathrm{Rb}$ ) e a composição isotópica $\delta \mathrm{C}^{13}$ (valores altos) conduziram os autores a pensar em ambiente com características mais de água salgada que de água doce. Acresce o fato de que na região de Anhembi (SP) foram encontrados calcários estromatolíticos nesta formação, embora, segundo Paulo G. Soares e Antônio Thomaz Filho, não sejam típicos de águas salgadas. 
h) A própria existência de sedimentação calcária, a presença de períodos de ressecação a que foram submetidos os sedimentos e principalmente os valores altos apresentados por $\mathrm{O}^{18}$ indicam para esses calcários um ambiente de intensa evaporação (clima semi-árido?).

Agradecimentos Os autores agradecem à Fundação de Amparo à Pesquisa do Estado de São Paulo (FAPES1) pelo auxílio concedido para as despesas de campo, ao Dr. Marcos Berenholc pelas análises por fluorescência de raios $\mathrm{X}$, ao Sr. Alain Lombart que auxiliou os autores nos trabalhos de campo e ao Sr. João Gobbo, proprietário da Fazenda São Vicente, que recebeu gentilmente os autores tendo franqueado as pedreiras para as observações e coleta de amostras. Agradecimentos são devidos também aos professores doutores Setembrino Petri, Sérgio E. do Amaral e Vicente José Fúlfaro pela leitura crítica do manuscrito.

\section{BIBLIOGRAFIA}

BEURLEN, K, - 1953 - Gonsiderações sobre alguns lamelibrânquios das camadas Teresina no Paraná, DGM-DNPM, Rio de Janeiro, Bol., 142: 41

CRAIC, H. - 1957 - Isotopic standards for carbon and oxygen and correction factors for mass spectrometric analysis of carbon dioxide, Geochim. et Cosmochim. Acta, 12: 133-149

DE GIOVANI, W. F., SALATI, E., MARINI, O. J. e FRIEDMAN, I. - 1972 - Unusual isotopic composition of carbonates from the Irati Formation, Brazil (no prelo)

FAIRBAIRN, H.W. e HURLEY, P. M. - 1970 - Evaluation of X-ray fluorescence and mass spectrometric analysis of $\mathrm{Rb}$ and $\mathrm{Sr}$ in some silicate standards, 18 th. Ann. Rept. U. S. A.E. C. AT (30-1), 183L, M.I. T.: 135-143 pp.

FOLK, R. L. - 1968 - Petrology of Sedimentary Rocks, 2." ed., The Univ. of Texas, Hemphill's, $170 \mathrm{pp}$.

FRIEDMAN, G. M. - 1958 - Determination of sieve analysis distribution from thin section data for sedimentary petrological studies, J. Geol, 66: 394-416

FRIEDMAN, G. M. - 1965a - In defense of point counting analysis: A discussion, Sedimentology, 4: $247-249$

FRIEDMAN, G. M. - 1965b - In defense of point counting analysis: hypothetical experiments versus real rocks, Sedimentology, 4: 252-253

GUimarã đis, J. E. P. - 1952 - Calcário no Estado de São Paulo, IGG, Sæo Paulo, Bol., 32: 64

KEITH, M. L. e WEBER, J. N. - 1964 - Carbon and oxygen isotopic composition of selected limestones and fossils, Geochim. et Cosmochim. Acta, 28: $1787-1816$

KRUMBEIN, W. C. e SLOSS, L. L. - 1963 - Stratigraphy and Sedimentation, 2." ed., W. H. Freeman and Co., $660 \mathrm{pp}$.

McCREA, J, M. - 1950 - On the isotopic chemistry of carbonates and a paleotemperature scale, J. Chem. Phys., 18: 849-857

McKEE, E. D. e WEIR, G. W. - 1953 - Terminology for stratification and cross stratification, Bull. Geol. Soc. Amer., 64: 381-390

MENDES, J. C. e PETRI, S. - 1971 - Geologia do Brasil, Instituto Nacional do Livró (MEC), Rio de Janeiro, Geologia, tomo 9: $207 \mathrm{pp}$.

MEZZALIRA, S. - 1964 - Grupo Estrada Nova, in Geologia do Estado de São Paulo, IGG, São Paulo, Bol., 41: 63-84

PETRI, S. e SUGUIO, K. - 1970 - Sobre microestilólitos da Formação Irati (Permiano) dos arredores de Assistência, Município de Rio Claro, Estado de São Paulo, An. Acad. Bras. Ciên., 42 (3): 501-506

PINCUS, H. J. - 1956 - Some vector and arithmetic operations on two dimensional orientation variates, with application to geological data, J. Geol., 64 (6): 533-558

REYNOLDS, R. G. - 1963 - Matrix corrections in trace element analysis by X-ray fluorescence estimation of the mass absorption coefficient by Compton scattering, The Amer. Mineral., $48(9-10): 1133-1143$

SUGUIO, K. - 1973 - Formação Bauru: Calcários e sedimentos detríticos associados (2 vol.). Tese de Livre-Docência, Instituto de Geociências da Univ. de São Paulo, 236 pp. (inédita) 
TANNER, W.F. - 1967 - Ripple mark indices and their uses, Sedimentology, 9: 89-104

WALKER, R.G. - 1963 - Distinctive types of ripple-drift cross lamination, Sedimentology, 2 (3): $173-188$

WENTWORTH, C. K. - 1922 - A scale of grade and class terms for clastic sediments, J. of Geology, 30: 377.392

WHITE, I. G. - 1908 - Relatório sobre as coal measures e rochas associadas do sul do Brasil, Rel. final da Com. de Est. das Minas de Carvão de Pedra do Brasil, Rio de Janeiro, Parte 1, pp. $1-300$ 